\title{
On-Orbit Propulsion System Performance of ISS Visiting Vehicles
}

\author{
Mary Regina M. Martin ${ }^{*}$, Robert A. Swanson ${ }^{\dagger}$, and Ulhas P. Kamath ${ }^{\ddagger}$ \\ The Boeing Company, Houston, TX 77059 \\ and \\ Francisco J. Hernandez $^{\S}$ and Victor Spencer ${ }^{* *}$ \\ NASA Lyndon B. Johnson Space Center, Houston, TX 77058
}

\begin{abstract}
The International Space Station (ISS) represents the culmination of over two decades of unprecedented global human endeavors to conceive, design, build and operate a research laboratory in space. Uninterrupted human presence in space since the inception of the ISS has been made possible by an international fleet of space vehicles facilitating crew rotation, delivery of science experiments and replenishment of propellants and supplies. On-orbit propulsion systems on both ISS and Visiting Vehicles are essential to the continuous operation of the ISS. This paper compares the ISS visiting vehicle propulsion systems by providing an overview of key design drivers, operational considerations and performance characteristics. Despite their differences in design, functionality, and purpose, all visiting vehicles must adhere to a common set of interface requirements along with safety and operational requirements. This paper addresses a wide variety of methods for satisfying these requirements and mitigating credible hazards anticipated during the on-orbit life of propulsion systems, as well as the seamless integration necessary for the continued operation of the ISS.
\end{abstract}

\section{Nomenclature}

$\begin{array}{ll}\Delta T & =\text { change in temperature in }{ }^{\circ} \mathrm{C} \\ \Delta V & =\text { change in velocity in } \mathrm{m} / \mathrm{s} \\ F & =\text { thrust in } \mathrm{kg}_{\mathrm{f}}\left(1 \mathrm{~kg}_{\mathrm{f}}=9.807 \mathrm{~N}\right) \\ I_{s p} & =\text { specific impulse in seconds } \\ K_{1} & =\text { constant derived from the acceptance test data for each type of thruster } \\ K_{2} & =\text { constant derived from the acceptance test data for each type of thruster } \\ m & =\text { mass of propellant consumed in } \mathrm{kg} \\ P_{\text {avg }} & =\text { average pressure of all tanks feeding a thruster in } \mathrm{kg} / \mathrm{cm}^{2} \\ T_{\text {on }} & =\text { total on-time in seconds }\end{array}$

\section{Introduction}

$\mathrm{T}$ housands of investigators from around the globe have utilized the ISS since its inception as an orbiting laboratory to perform unique research in such diverse fields as biology and biotechnology, Earth and space science, human physiology and performance, education, physical sciences and technology. Earth observation capabilities on the ISS serve as a rapid-response platform to monitor climate change, disasters and urban growth on Earth. The research in microgravity environments has inspired future scientists, engineers and space explorers while advancing our understanding of key issues affecting space exploration and mastering the materials technology to

\footnotetext{
* Propulsion System Engineer, Anadarko Industries, Houston, TX 77059

${ }^{\dagger}$ Propulsion/VIPeR Systems Engineer, Boeing Defense, Space \& Security, MC HB5-30

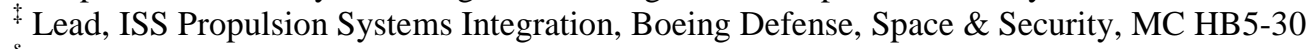

$\S$ ISS Propulsion System Engineer, NASA Johnson Space Center, Propulsion and Power Division, EP4. AIAA Member.

** ISS Propulsion System Manager, Propulsion and Power Division, EP4. AIAA Member.
} 
enable easier access to space. The ISS partnership is a model of what will be needed if an ambitious program of exploration beyond low-Earth orbit (LEO) is to move forward. Extending the service life of ISS systems beyond 2020 and possibly to 2028 would ensure continued utilization of this unique platform to facilitate cutting edge research to the benefit of humanity.

Uninterrupted research on the ISS requires a robust fleet of space vehicles enabling crew rotation, delivery of science experiments, replenishment of propellants and supplies and augmentation of propulsive capabilities. Since the launch in 1998 of its first module the Zarya, or FGB, crew and cargo visiting vehicles have provided the ISS its lifeblood of cargo and consumables, including propellants. Multiple international partners and commercial contractors have designed, built, and operated these visiting vehicles. In spite of their unique design features tailored to address differences in functionality, operational and performance characteristics, the vehicles must meet a range of interface requirements, along with safety and operational requirements, stipulated in a dedicated set of documents such as the common Safety Requirements Document (SRD), individual Interface Requirements Document (IRD), Segment Specification, ISS Flight Rules, etc., such that the mission objectives are met without compromising ISS safety. Seamless integration of these vehicle systems on the ISS requires careful mission planning, safety coordination and system analyses.

A common denominator that integrates vehicles with the ISS is NASA's Systems Engineering and Integration (SE\&I) process, implemented by the Vehicle Integrated Performance Environments and Resources (VIPER) Team. As part of VIPER, the ISS Propulsion Team ensures that the visiting vehicle propulsion systems adhere to systems engineering best practices to meet ISS operational and safety requirements. ${ }^{1}$

The propulsion systems of the ISS permanent elements, or modules, are of Russian heritage designs, and significant portions of Russian systems had been tested and flown on Mir space station prior to the construction of the ISS modules. The Zvezda, or Service Module (SM), for example, is an enhanced version of the Mir base block module and was originally built to support the Mir 2 program. As a result, much of the flight data from Mir's propulsion system is applicable in ISS operations and integration. The heritage and lessons learned during the past decades of both Russian and American spaceflight have been applied to the integration of visiting vehicles to the ISS.

The crew and cargo vehicles that have visited the ISS include the Progress and Soyuz vehicles ${ }^{2}$, the Space Shuttle Orbiter, European Space Agency's (ESA's) Automated Transfer Vehicle (ATV) ${ }^{3}$, Japan Aerospace Exploration Agency's (JAXA's) H-II Transfer Vehicle (HTV) ${ }^{4}$, and Space Exploration Technologies Corporation's (SpaceX's) Dragon. Orbital Sciences Corporation's (Orbital's) Cygnus is scheduled to fly for the first time to the ISS during 2013 and, like SpaceX, will fly a number of flights under the Commercial Orbital Transportation Services (COTS) prior to commencing resupply missions under the Crew Resupply Services (CRS) contract. Exact specifications of these vehicles are beyond the scope of this paper; however an attempt is made to present the differences in basic design features, performance, and operations. Also not included in this paper are details related to the future visiting vehicles that are under development for the Commercial Crew Integrated Capacity (CCiCAP) and Commercial Certification Program (CCP) contract by Boeing, SpaceX and Sierra Nevada.

\section{Propulsion System Considerations}

Design and operations are driven by requirements and constraints levied by the ISS Program, by international agreements, mission goals, and the intended purpose of the visiting vehicle. These all cover a variety of different purposes and scenarios. The fragility of human life and health imposes stringent requirements on the vehicle to maintain crew safety. In addition, as the most valuable space asset, a need for continued operation and performance of the ISS without being adversely affected by the visiting vehicles makes the design and operational requirements even more demanding.

The intended purpose of the vehicle and the mission goals require the visiting vehicle to be capable of successfully arriving at and departing from the vicinity of the ISS, successfully rendezvousing with the ISS, and completing a docking or berthing. A cargo vehicle is used for logistics resupply and delivers dry cargo as well as water, propellant, and atmospheric gases to the ISS. Propellant resupply also includes propellant transfer to the SM and through the SM to the FGB for propellant storage. The cargo aboard must be delivered either by the crew, which requires additional safety factors so that the crew can enter the vehicle without risk of injury or death, or autonomously, as in the case of propellant refueling or external payloads. The propulsion systems in the visiting vehicles mandate additional considerations such as erosion and structural loads induced by thruster plume impingement on ISS hardware, ISS contamination caused by propellant leakage, mechanical and thermal stresses, and the risk of thruster failures during firing. 
In order to protect both the crew and the ISS hardware, NASA has defined a set of priorities to which all visiting vehicles must adhere. Crew safety is always the requirement of highest priority, followed by the safety of the ISS hardware. The ISS lifetime must be protected, for all of the components of the ISS have a limited lifespan, either in operational on-time and number of cycles, or in how much wear they can sustain before performance is degraded. For example, thruster plumes can erode the solar arrays which subtracts from their lifetime and therefore from the lifetime of the ISS. The Service Module (SM) thrusters have certified lifetime limits based on the cumulative ontime and the number of times that they are fired (i.e., number of cycles). Protection of the docking and berthing capability of the ISS is important, as the ISS would be incapable of long-term operation without the continuous stream of visiting vehicles. The safety of the visiting vehicle is also critical, followed by overall mission success, e.g. the continuation of the planned mission objectives, including propellant transfer, cargo delivery, vehicle testing, etc.

The SRD and IRD formally lay out the requirements levied on all visiting vehicles by the ISS Program. The SRD defines a set of hazards, all of which are common to propulsion systems regardless of design, and for each individual vehicle, the IRD maps these hazards to the design of the specific vehicle. The IRD, for instance, mandates a certain number of inhibits, mechanical, electrical or both, against these potential hazards, depending on their severity. In addition, the IRD requires strict quality control in the manufacturing, assembly, and loading of propulsion systems in order to mitigate many of these common dangers. ${ }^{5}$

Hazard control can be defined as the use of design and operational measures to reduce the likelihood of hazardous effects. Provisions of appropriate design features to eliminate the hazard, materials, parts selections, and safety factors and design considerations to include damage control, containment, isolation of potential hazards, and failure tolerance considerations are all part of hazard control. Incorporating safety devices reduces the hazards to acceptable levels, and the use of warning devices, crew operational procedures, and protective clothing and/or equipment minimizes the effects of potential hazards ${ }^{6}$.

The three most common propulsion system hazards are: collision, contamination, and explosion. A significant number of causes can result in each of these hazards, and their mitigation is a main driver of propulsion system design.

NASA has placed these hazards into two categories: catastrophic and critical. The SRD defines a catastrophic hazard as a condition resulting in severe personnel injury, loss of life or loss of a human space vehicle. A critical hazard is one resulting in a non-disabling personnel injury, severe occupational illness, loss of a major element or functionality in human space vehicle or a ground facility. The mitigation requirements depend on the category into which a hazard falls. A catastrophic hazard must be protected against by three independent inhibits, or be two fault tolerant, so that that no combination of two failures, two operator errors, or one of each can result in a catastrophic hazard. No single failure or single operator error can result in a critical hazard.

Fault tolerance is one of the preferred hazard control methods comprising functionally redundant systems to prevent failures from causing catastrophic consequences. For example, propellant tanks must be two fault-tolerant against over-pressurization, as a propellant tank rupture can result in catastrophe. Pyrotechnic valves that could cause a catastrophic event in the case of premature firing must also be two-fault tolerant. ISS safety requires a minimum of three mechanical inhibits and three independent electrical inhibits to prevent an inadvertent thruster firing. At least two of the three required inhibits need to be monitored.

Other methods of addressing hazard control requirements are design for minimum risk (DFMR), isolation, and operational control. DFMR allows for unexpected events or anomalies by eliminating all credible failure modes within a specific operating range, demonstrated by test and analysis showing significant margin over the operating limit. Procedures should be written clearly and precisely to avoid operator error and protect against hazards such as an incorrect valve configuration that might inadvertently allow pressurant to enter the propellant tanks. When not in use, portions of the propulsion system can be isolated to protect other parts of the vehicle. Implementation of the Fault Detection, Isolation and Recovery (FDIR) system is essential to monitor the health and operation of the propulsion system. If the FDIR detects that the system is out of configuration or nearing a hazard, it can either abort the operation, isolate the problem or execute commands to prevent the hazard. For example, the FDIR constantly monitors the Guidance, Navigation and Control (GN\&C) system of a docking vehicle and if it detects incorrect variances in expected vehicle attitude and position, it will automatically command the vehicle to proceed on functionally redundant systems. If the errors continue to decrease the fault tolerance level, the FDIR will eventually abort the docking or berthing operations and place the vehicle in a safe trajectory away from the ISS. 


\section{Design Drivers for Pressure Systems}

One of the largest design drivers is the consideration of pressure. The pressurant and propellant are stored under high pressure, and the thrusters are open to space and experience vacuum conditions. The extreme environment mandates a system robust enough to operate under all possible conditions and scenarios.

Water hammer, or sudden surge transient pressure, presents a significant challenge for spacecraft propulsion systems. Variation in spacecraft thermal environment can create large pressure differences across the isolation valves in fluid lines. Opening a fast response valve with sufficiently high pressure difference across can lead to water hammer. Thus when a propulsion system is primed after launch or on orbit, water hammer could potentially cause damage to the valves, components or line segments.

Some vehicles solve the problem of water hammer during system activation by using slow-acting motor valves, which decrease pressure surges. Other systems use a flow-restricting orifice, venturi, or flow limiter plate to reduce the maximum surge pressure to a manageable level. HTV uses a novel method for managing the pressure surge by heating up the propellant lines to recover the downstream pressure before opening the isolation valves ${ }^{7}$. In some cases, manifolding line segment dead ends together and extending the line segments mitigates the maximum surge pressure $^{8}$. All of these, however, require additional hardware, and in some cases require re-priming of the propulsion system every time that it is activated for use.

Propulsion system components are rated for a Maximum Design Pressure (MDP), which is defined as the highest pressure driven by the maximum relief pressure, maximum regulator pressure, maximum temperature and transient pressure excursions ${ }^{9}$. MDP for manned spacecraft pressurized systems is collectively the pressure resulting after two failures. For example, MDP accommodates any worst combination of two credible failures of the relief valve and/or regulator. Some components are designed with a Maximum Expected Operation Pressure (MEOP), or the maximum pressure at which the system or component nominally operates in an actual application, which includes the effects of temperature, transient peaks, vehicle acceleration, and relief valve tolerance ${ }^{10}$. The MDP shall have sufficient margin above the MEOP to account for contingency situations. During qualification, each propulsion system component is required to be tested to and meet higher factors of safety called proof pressure and

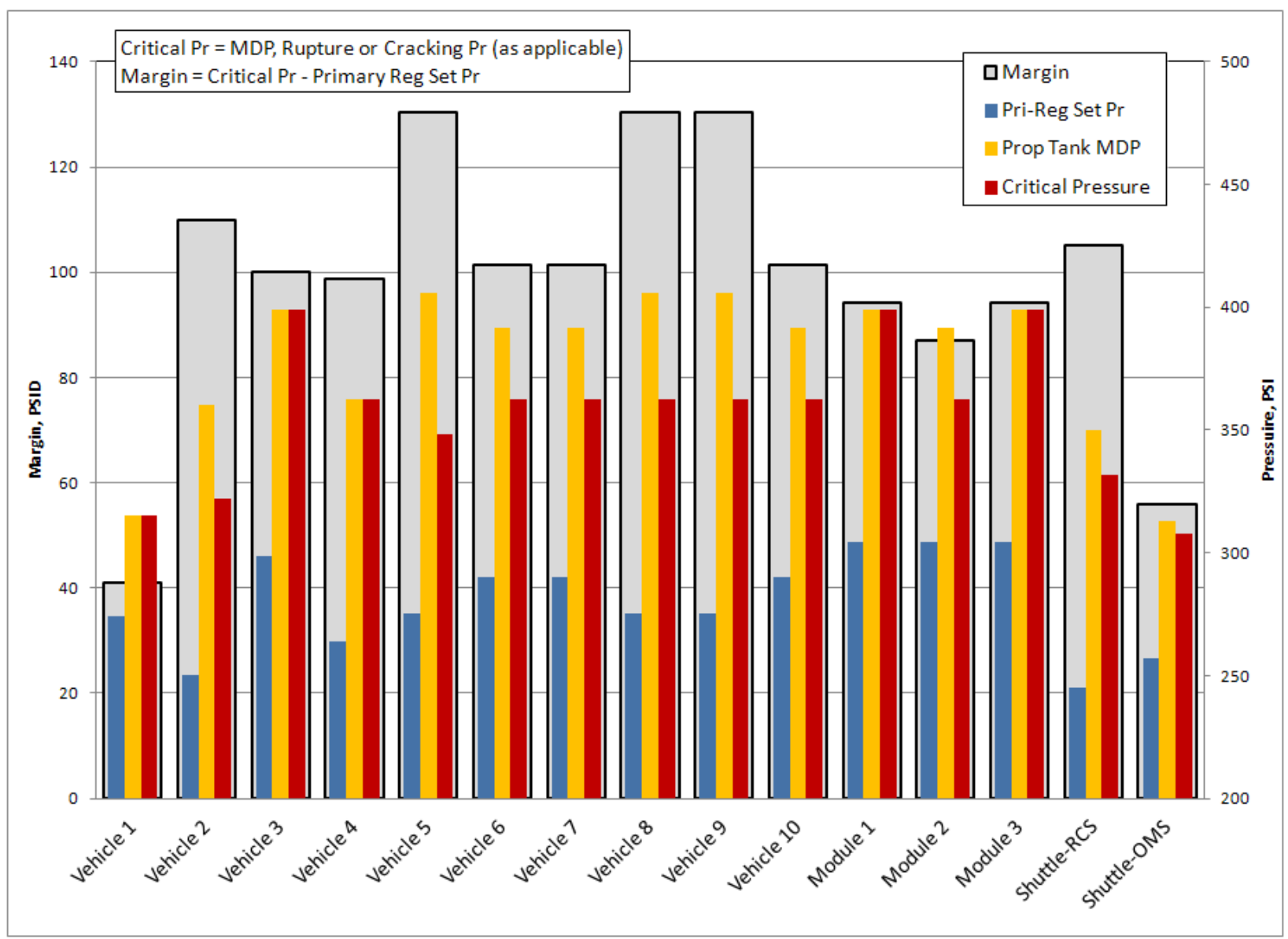

Figure 1. Visiting Vehicle Design Parameters

American Institute of Aeronautics and Astronautics 
burst pressure. For low pressure components, proof pressure and burst pressure are usually defined as 1.5 times MDP and 2.0 times MDP, respectively. For high pressure components and lines/fittings, proof pressure and burst pressure are typically defined as 1.5 times MDP and 4.0 times MDP.

Visiting vehicle propulsion systems must protect against over-pressurization, which might result, for instance, from a change in temperature or a pressure regulator failure. The most common protections are burst disks and relief valves. The majority of ISS visiting vehicles have relief valves on the propellant tanks, and several have both relief valves and burst disks. However, a few of the vehicles have neither, and these rely on the robustness of their propulsion system design and a wide margin for pressure increase before possibility of rupture becomes a real threat.

Primary regulator set point is an important design parameter. All other pressure levels - lock up pressures, set point of the secondary regulator, maximum pressure at which a propellant tank arrives at the ISS, with or without a blowdown phase - depend on this single parameter. Assuming no change in the fill fraction of propellant tanks (defined as the ratio of propellant volume to tank volume), subsequent increase in pressure depends on the initial conditions (pressure, temperature and fill fraction), change in temperature and the sensitivity of propellant vapor pressure and density to the temperature change. Generally, due to its higher vapor pressure, nitrogen tetroxide (NTO) tank has a higher over pressurization potential and is monitored closely by the ISS safety and operational teams.

Figure 1 compares some of the propulsion system design parameters selected by the visiting vehicles and permanent modules on the ISS. Some vehicles have two independent propulsion systems, one for its free flight and ISS integrated operations and another for resupplying ISS propulsion system. These are shown as different vehicles and modules in Figure 1.

For ease of comparison, a safety margin is defined as the difference between Critical Pressure and the set pressure of the primary regulator, where Critical Pressure is defined as the rupture pressure of the burst disk or cracking pressure of the relief valve, whichever is used to prevent over-pressurization. For the systems that do not

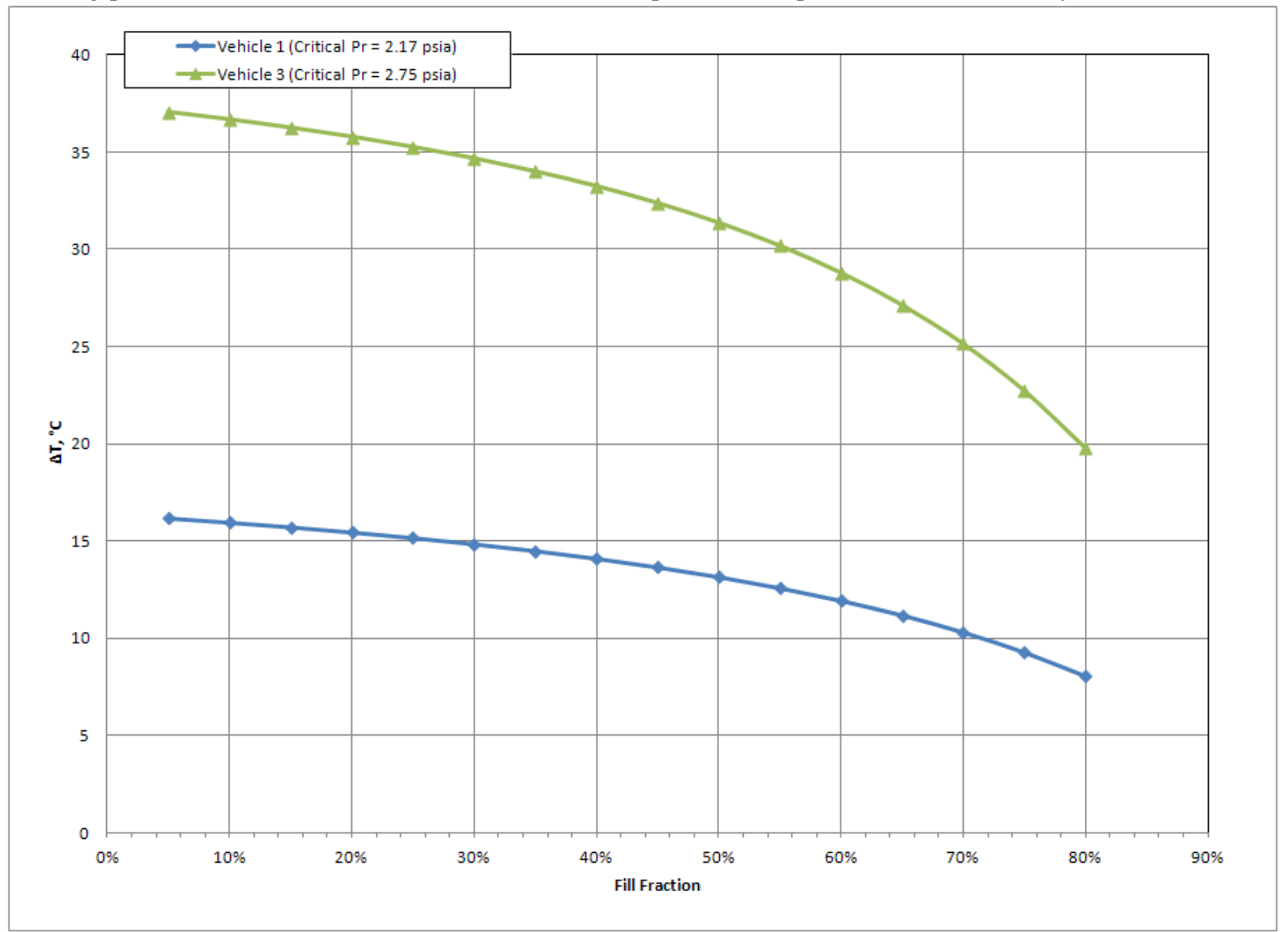

Figure 2. NTO Tank Over-Pressurization Potential. 
use rupture disk or relief valves for mitigating the over-pressurization risk, Critical Pressure is considered to be equal to the MDP of the propellant tank.

Figure 2 illustrates the significance of the Safety Margin by comparing the over pressurization potential in Vehicles 1 and 3, with an initial temperature of $15^{\circ} \mathrm{C}$ in both. ISS temperatures see the hottest or coldest temperatures during beta ${ }^{\dagger \dagger}$ angle extremes (depending on where the hardware is relative to the sun). The maximum temperature swing ( $\Delta \mathrm{T} \_$max) usually occurs when entering or leaving this beta period. Since NTO tank pressure variation is more susceptible to temperature excursions, the temperature increase $(\Delta \mathrm{T})$ that an NTO tank can sustain without causing over-pressurization is an important consideration and has to be more than its $\Delta \mathrm{T}$ _max for a given mission.

As seen in Figure 1, the margin is 40 psid in Vehicle 1 and 100 psid in Vehicle 3. For a $30 \%$ fill fraction, it can be seen in Figure 2 that Vehicle 1 reaches its Critical Pressure at a $\Delta \mathrm{T} \approx 15^{\circ} \mathrm{C}$, whereas Vehicle 3 would not be at over-pressurization risk until the $\Delta \mathrm{T}$ _max reaches $\sim 35^{\circ} \mathrm{C}$. While on the ISS, the propellant tank on Vehicle 3 would therefore be able to tolerate larger temperature changes than Vehicle 1 without the risk of reaching its critical pressure. A lower margin on the Space Shuttle propulsion systems was less of a concern due to its short mission duration, better thermal control and ability to vary its fill fraction during ISS integrated operations. Interestingly, the Apollo Command Module, Service Module and Lunar Module propulsion systems also benefited from similar features so as to be able to afford a lower margin.

Based on a survey of best practices used across various vehicles over the life of the space station, a 100 psid ( $0.7 \mathrm{MPa}$ ) margin is considered appropriate for safe operation, especially in the absence of mitigations discussed above.

\section{Integration and Operations}

In the same way that the IRD and SRD provide guidelines for design, flight rules dictate requirements for operation and integration and clearly identify responsibility and authority for mission operations ${ }^{11}$. Flight rules govern all aspects of the ISS Program's operations, and each visiting vehicle has its own dedicated volume. They are developed in a joint effort by Mission Operations Directorate (MOD), ISS subsystem specialists, and specialists from the organization that owns the vehicle. The following section discusses the flight rules and many of the aspects of operation they cover, as it applies to propulsion systems.

The purpose of flight rules is to integrate relevant engineering constraints, outline procedures for nominal mission operations, assign responsibility and authority, and plan a course of action for potential contingencies and anomalies prior to the actual mission. The harsh environment of space implies that the safety of the crew depends on the system's ability to react quickly to the loss of almost any system or portion of a system.

\section{A. Propellant Quantities and Management}

For a propulsion system, the first set of applicable flight rules are those governing propellant quantities. Micro gravity presents a number of challenges in gauging propellant quantities. The amount of propellant remaining in a tank is typically not directly measured due to weightlessness and the effects of acceleration upon the tank contents. Therefore calculation must be relied upon instead. Four primary methods of calculated propellant quantities have been used over the course of the ISS program, some with more success than others.

The first method is the Pressure-Volume-Temperature (PVT) method, which utilizes the ideal gas law ${ }^{12}$.The second method is a Burn-Time Integration (BTI). This utilizes the thrust and specific impulse of a thruster manifold to calculate the amount of propellant consumed by a particular thruster. The total consumption of each thruster is calculated using the formula:

$$
m=F * T_{o n} / I_{s p}
$$

where $m=$ mass of propellant consumed in $\mathrm{kg}, F=$ thrust in $\mathrm{kg}_{\mathrm{f}}, T_{\text {on }}=$ total on-time in seconds, and $I_{s p}=$ specific impulse in seconds. Thrust for a manifold of thrusters is determined by the formula:

$$
F=\left(K 1 * P_{a v g}\right)+K 2
$$

\footnotetext{
${ }^{{ }^{+\dagger}}$ Beta angle is the angle measured between the Sun vector and the ISS orbital plane, which is inclined $51.6^{\circ}$ to the Earth's equator.
}

6

American Institute of Aeronautics and Astronautics 
where $F=$ thrust in $\mathrm{kg}_{\mathrm{f}}$ and $P_{\text {avg }}=$ the average pressure of all tanks feeding the thruster in $\mathrm{kg} / \mathrm{cm}^{2}$, with a maximum possible value equal to the nominal thrust of that thruster. The constants $K 1$ and $K 2$ are derived from the acceptance test data for each type of thruster.

These two methods, PVT and BTI, are the primary methods of propellant quantity gauging for the ISS Program. However, additional methods have been used as well, namely a physical measuring device utilizing the properties of bellows tanks and a method utilizing radio frequencies.

For each vehicle, the flight rules define three propellant quantities as the amounts required for certain critical operations. This helps the mission operations team to know what the propellant consumption priorities are, which in turn allows them to make decisions if the propellant level falls below the requirement at certain points during the mission. In general, the most critical priority level is the propellant required for a worst-case undocking, release, or abort, and a controlled re-entry. The second priority level usually includes the propellant required for nominal approach and docking/capture. The third priority level usually includes other nominal mission objectives and the possibility of a re-rendezvous attempt in the case of an abort. The flight rules define these and potentially other priority levels and what falls into each category for each vehicle. However, the actual amounts required for each priority are assigned on a mission-specific basis.

For the most part, visiting vehicles operate in regulated pressure mode from system priming all the way through docking or capture. Some missions have been accomplished in blowdown mode near the ISS. Operating in blowdown mode reduces the risk of ISS hazards caused by the high pressure system. However, a propellant tank repressurization could potentially be required, depending on how far the pressure falls during blowdown mode operations. Based on the approved design and operational controls against the potential hazards, flight rules allow predetermined operational modes during ISS proximity operations.

\section{B. Proximity Operations}

Once a vehicle reaches the vicinity of the ISS and begins Proximity Operations, the bulk of the flight rules come into effect. Before that point in free flight, the ISS Program has little input into the operations of a vehicle, although ISS Program Specialists, including the Propulsion Team, continuously monitor the health and status of the vehicle.

A visiting vehicle uses one of the two methods available for mating to the ISS structure: autonomous docking, or capture and berthing. The former allows the vehicle to dock to the ISS using its own propulsion system. This is the method used by the Progress, Soyuz, Shuttle, and ATV.

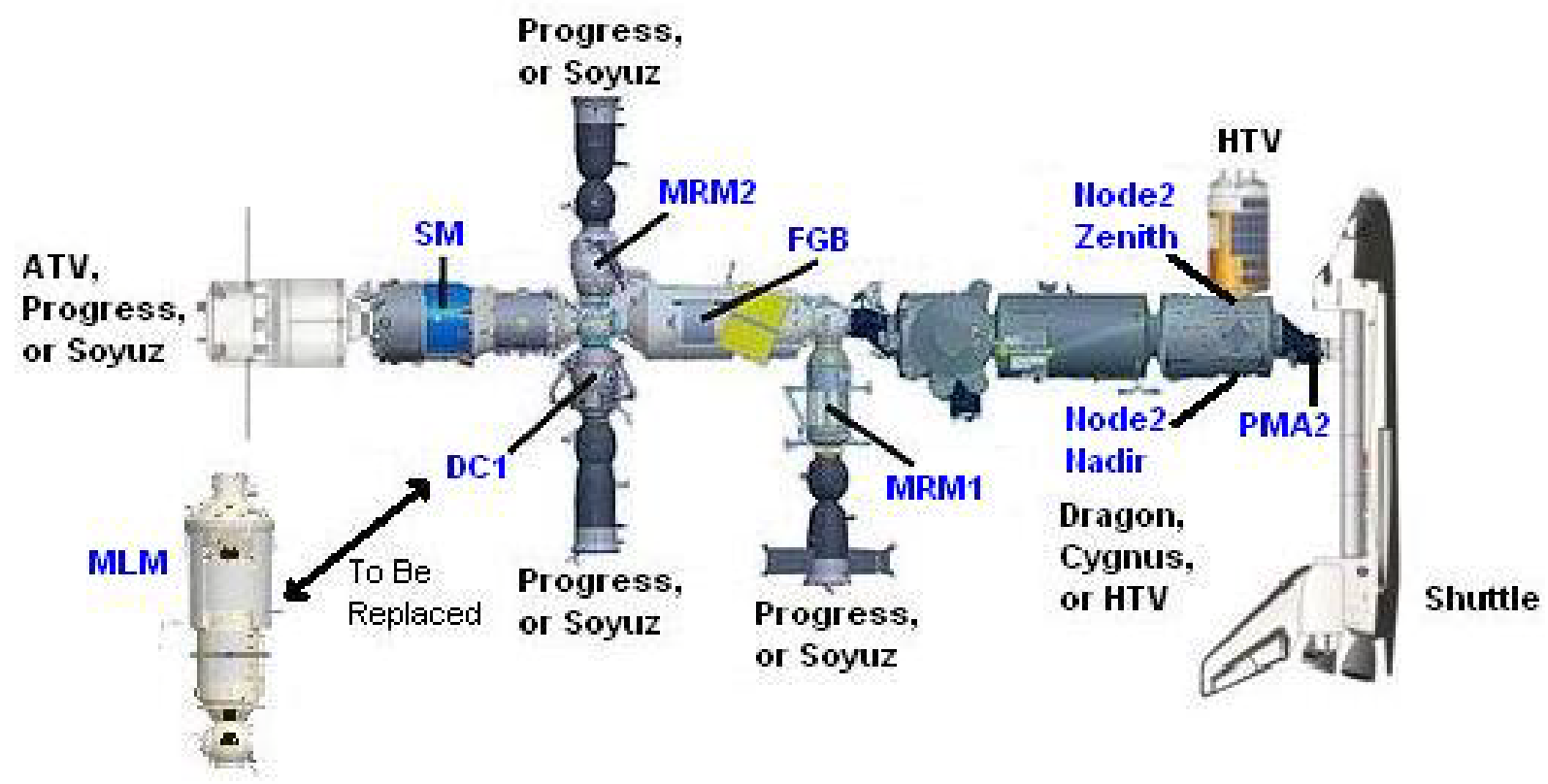

Figure 3. ISS Visiting Vehicle Docking and Berthing Ports.

The second mating method, berthing, requires the vehicle to approach the ISS and enter a capture box where the Space Station Remote Manipulator System (SSRMS) arm reaches out and captures the vehicle. The visiting vehicle transitions to freedrift by inhibiting its thrusters prior to being captured by the SSRMS. The SSRMS then maneuvers the vehicle into place and berths it to one of the Node 2 berthing ports, usually Node 2 Nadir. Dragon, Cygnus, and HTV all use this method. 
Both mating methods require a precise use of the visiting vehicle's propulsion system. Rendezvous is one of the most critical portions of the entire mission, as collision with the ISS is a concern. At this stage the fault tolerance requirements and FDIR are critical. Motion control capability is of vital importance, as a vehicle 'dead in the water' in the vicinity of the ISS presents a large number of serious risks. The exact number of thruster failures and thruster set failures allowed during Proximity Operations depends on the vehicle design, but a positive fault tolerance is required at every point.

Figure 3 shows a diagram of the configuration of the ISS visiting vehicle ports, including the position of the Multipurpose Laboratory Module (MLM), scheduled for the end of 2013. Four main Russian docking ports currently exist: the SM-Aft port, the Mini Research Module (MRM) 1 Nadir port, the MRM2 Zenith port, and the Docking Compartment-1 (DC-1) Nadir port. DC-1 currently is docked to the SM Nadir and will be undocked and deorbited and replaced by the MLM, which has its own docking port. All current docking vehicles use these ports. In addition, the Pressurized Mating Adaptor 2 (PMA2) docking port is attached to Node 2 on the US side, which allows US crew vehicles to dock. This port was utilized by the Space Shuttle Orbiters but is now unused due to the lack of a US crew vehicle. In addition, the US Segment has two berthing ports: Node 2 Nadir and Node 2 Zenith.

Ideally, closing the propulsion system isolation valves and inhibiting the thrusters provides necessary barriers against leaking thrusters, inadvertent thruster firings and overpressurization concerns during ISS integrated operations. However, if this is not possible due to vehicle specific constraints, adequate controls shall be in place to mitigate hazards to ISS assets. For instance, if required number of mechanical inhibits cannot be put in place to prevent potential leakage or inadvertent firing, electrical inhibits combined with a successful leak check prior to transitioning the propulsion system to dormant mode may be acceptable. Each specific case needs to get formal ISS Program approval.

Once an autonomous vehicle docks to an ISS port, the thrusters are immediately inhibited so no thrusters can fire when the locking mechanisms are activated. Once the vehicle is secured, the propulsion system remains isolated unless they are to be used to support ISS attitude control. Currently, the Progress and the ATV are the only vehicles

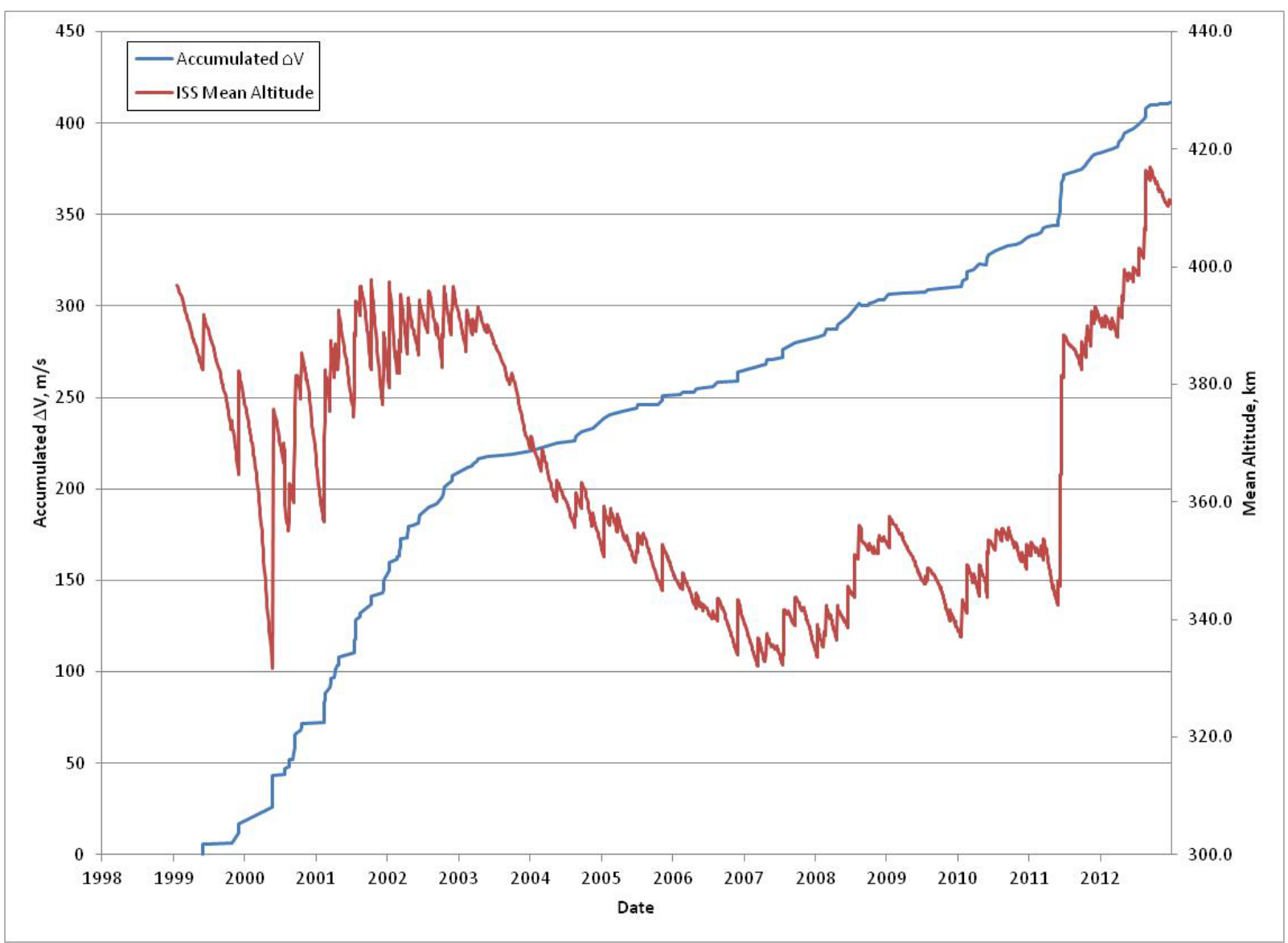

Figure 4. ISS Mean Altitude vs. Accumulated $\Delta \mathrm{V}$

American Institute of Aeronautics and Astronautics 
capable of providing propulsive support to the ISS. However, the Soyuz can be used in very rare contingency cases, as its propulsion system is to be preserved for crew return. The US Orbiter also provided propulsive support during mated missions. If the vehicle can be used for propulsive support, the flight rules governing operating temperatures and pressures are followed to ensure nominal performance.

Visiting vehicles must prepare for departure if any failure while docked or berthed would cause the risk of damage to the ISS or the crew. For example, if the propulsion system develops a leak that cannot be isolated, the visiting vehicle must prepare to depart immediately to prevent contamination and explosion hazards, while still maintaining the ability to depart safely with available propellants.

\section{ISS Propulsive Support}

ISS propulsive control is managed by the Service Module computers. The primary mode of operation is under Russian Control using the Russian software, called Russian Segment Motion Control System (RS MCS). However, a US-only thruster (USTO) mode of operation is also possible. This mode puts the RS thrusters under US command. Under both modes, a wide range of thruster configurations are available for both translation and attitude control. The Service Module provides control in all three axes (although its roll control is not particularly efficient), and a Progress or an ATV at the SM-Aft docking port can provide control in all three axes as well. A Progress at DC-1

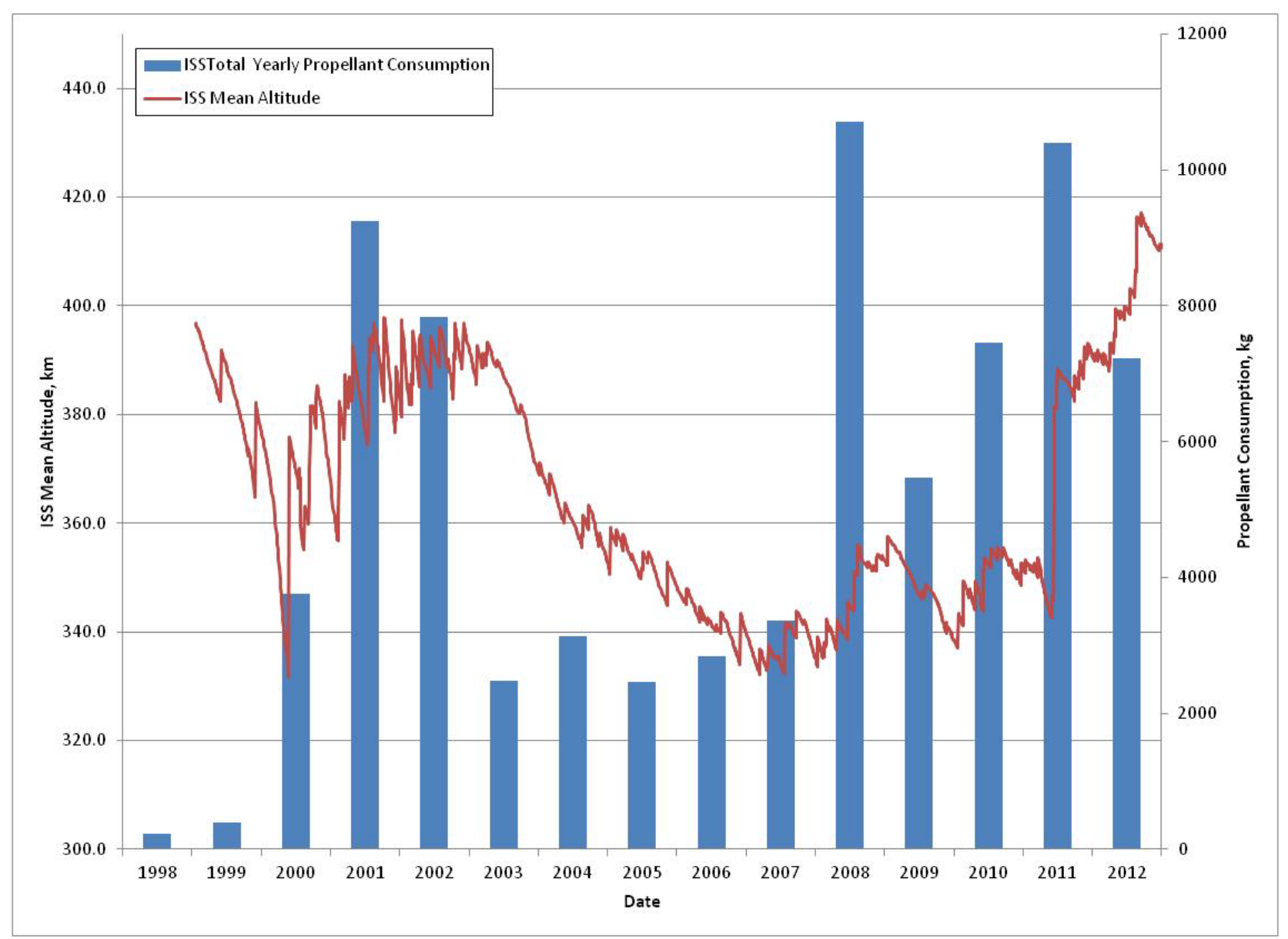

\section{Figure 5. ISS Mean Altitude vs. Yearly Propellant Consumption.}

Nadir can provide roll control. When MLM is integrated with the ISS, Progress docked to the MRM2 Zenith port and MLM are likely to be the primary sources for roll control, essentially eliminating the need for SM roll thrusters which are approaching the end of their operational lifetime. For translation, four options are currently available, depending on the vehicle configuration. ISS reboost can be achieved by firing aft thrusters on a Progress or ATV docked at SM-Aft. A Progress docked to DC-1 Nadir can also perform a less efficient but still successful reboost using its mid-ring thrusters, although it cannot provide a $\Delta \mathrm{V}$ greater than $0.7 \mathrm{~m} / \mathrm{s}$ due to thruster on-time restrictions. If the SM-Aft port is vacant, the SM Main Engines can perform orbit reboosts. 
A significant portion of ISS thruster control is dedicated to translational control, mostly in the form of reboosts. Figure 4 shows the accumulated $\Delta \mathrm{V}$ against the ISS mean altitude over the life of the ISS Program. Over $400 \mathrm{~m} / \mathrm{s}$ of $\Delta \mathrm{V}$ has been imparted to ISS since the launch of the FGB in 1998, which translates to a significant portion of the ISS propellant consumption. Figure 5 shows the mean altitude compared against yearly propellant consumption. In the years that the altitude was allowed to decay naturally (e.g. 2003 - 2006), the yearly propellant consumption was significantly lower than in years in which frequent translational maneuvers were used to change the ISS mean altitude in a significant manner. It may be noted that after Space Shuttle Columbia disaster in 2003, logistics and crew flights to the Station were limited to the Russian Progress and Soyuz vehicles for about two years. Following a successful return-to-flight mission in 2005, which fulfilled the safety evaluation and test objectives, regular Space Shuttle flights to the ISS resumed in 2006. Propellant usage increased dramatically in 2008 to support a relatively busy assembly period in ISS construction, featuring four Shuttle flights, six Russian crew/cargo vehicles, one ATV and three EVAs. ISS orbit was raised by about $20 \mathrm{~km}$ and the overall mass increased by over $20 \%$, with the arrival of several new modules in 2008.

Three ATV vehicles - Jules Verne (2008), Johannes Kepler (2011) and Edoardo Amaldi (2012) - together performed a total of 25 maneuvers to provide $67 \mathrm{~m} / \mathrm{s}$ of ISS reboost at an expense of $8400 \mathrm{~kg}$ of propellants. Attitude control propellants during these reboost maneuvers accounted for an additional $1926 \mathrm{~kg}$. A 40\% growth in ISS mass during the assembly period 2008-2011 had caused a corresponding increase in the reboost propellant cost.

An important function of visiting vehicles from a propulsion system standpoint is the supply of delta- $\mathrm{V}$ both through refueling capability and through direct propulsive support. Figure 6 shows the on-board propellant capacity of the ISS along with yearly consumption. Onboard propellant capacity increased by about $850 \mathrm{~kg}$ after the SM docked and became part of the ISS in July, 2000. The propellant consumption shown by vertical bars includes propellants supplied by various visiting vehicles. Figure 7 shows the accumulated amount of propellant consumed

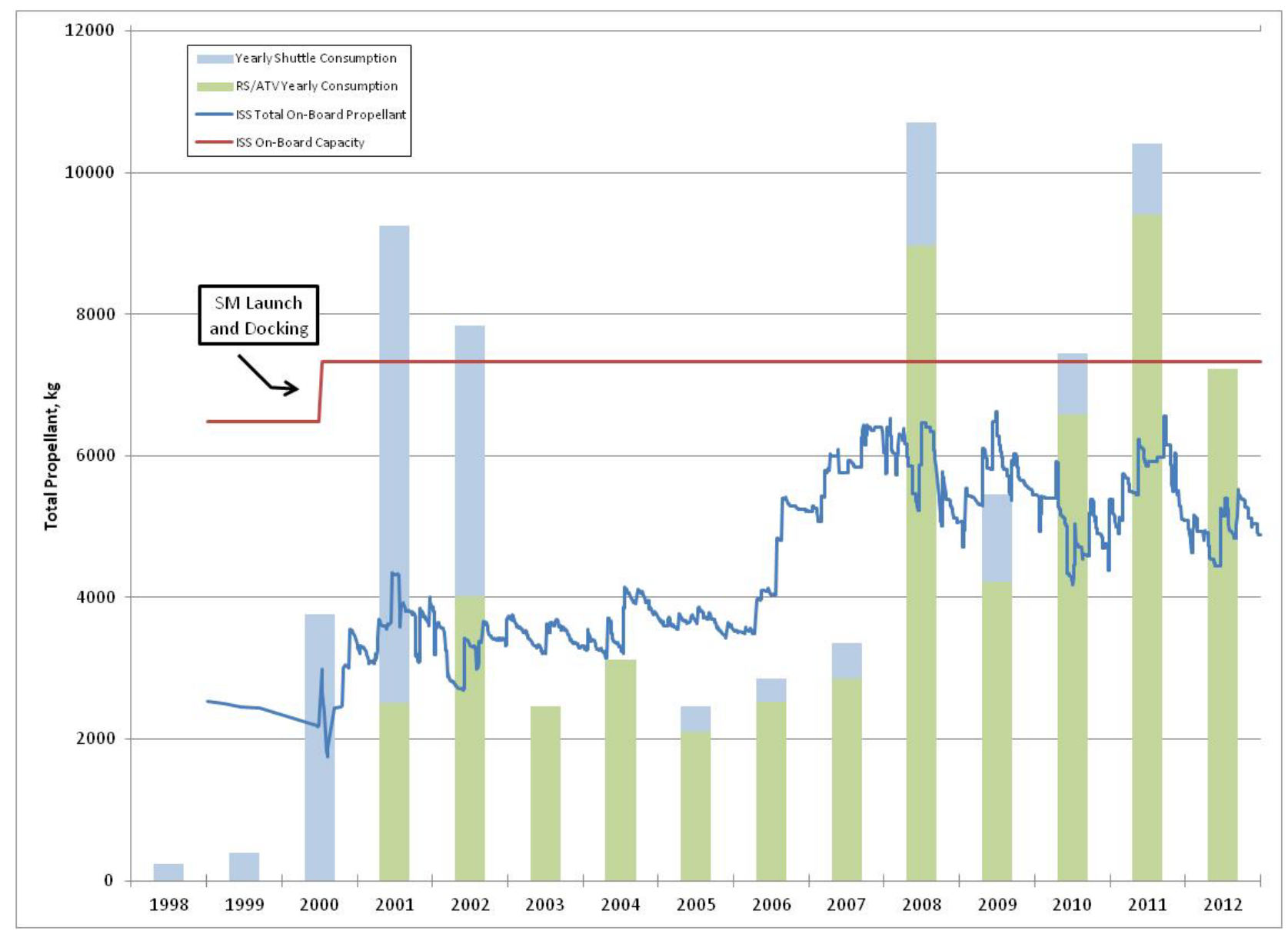

Figure 6. ISS On-Board Propellant Load vs. Yearly Propellant Consumption 
over the life of the Program. With the exception of the propellant carried up by the FGB and SM at their launch, all of the nearly $80,000 \mathrm{~kg}$ of propellant came up with visiting vehicles. This amount includes the propellant consumed by the visiting vehicle to provide propulsive support and the propellant manifested up to the ISS modules.

\section{Refueling}

Transferring propellant presents a unique set of challenges. Whether the propellant is being transferred into the ISS tanks for resupply or the propellant is being fed to the Progress thrusters during a propulsive event, the propellant must pass through the interconnect lines on the docking hatch. Before this can be done, a leak check is performed by pressure decay method. In this process, gaseous pressurant is fed into the interconnecting lines and held under pressure ( $210 \mathrm{psia}$ ) for 1 orbit while being monitored for leakage. If no pressure decay is observed, the vent valves on the docking port are then opened to allow the pressurant to escape into vacuum. After a successful

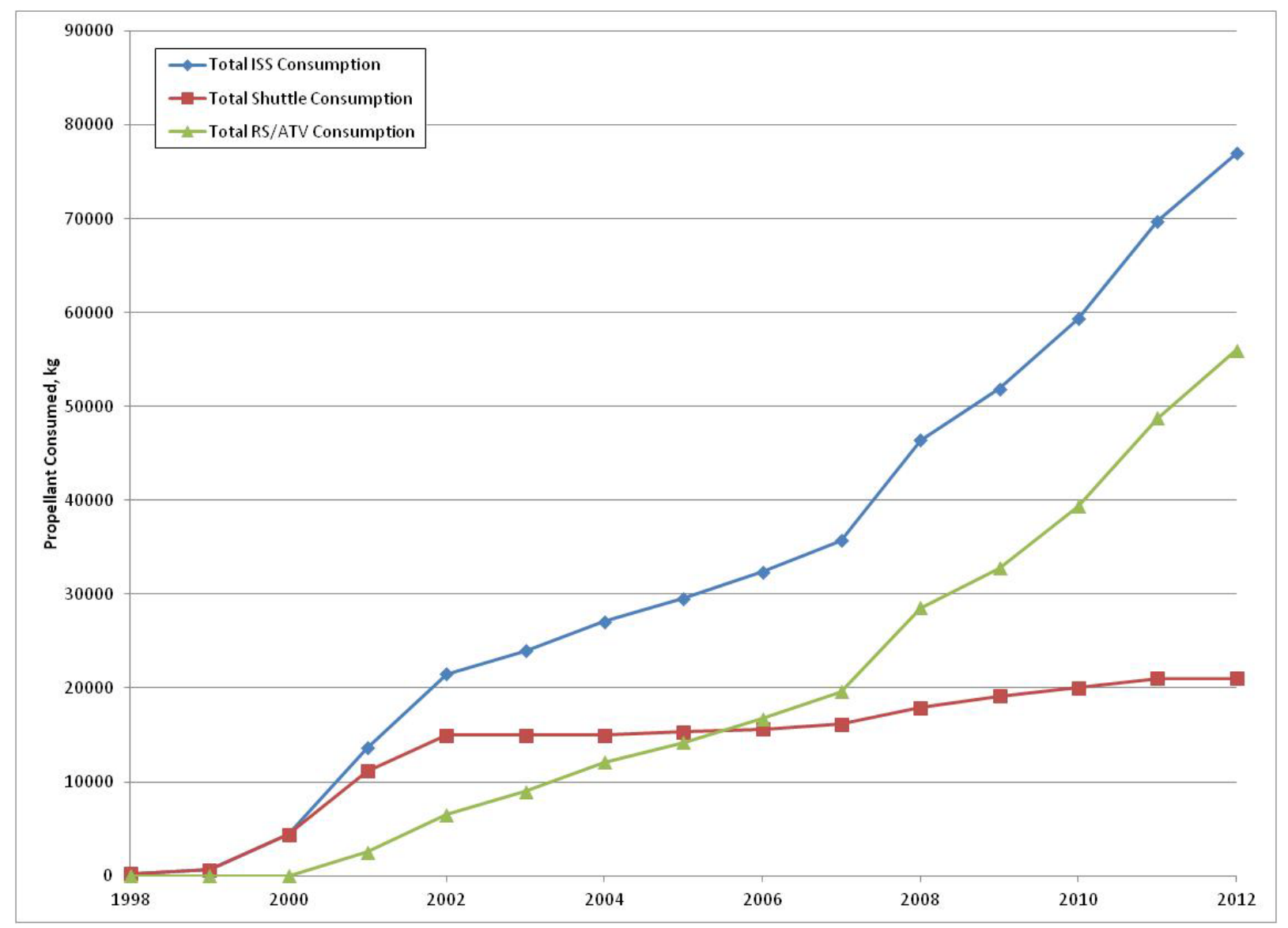

Figure 7. ISS Accumulated Propellant Consumption.

leak check, propellant transfer can be performed.

When the vehicle is ready to undock, it is necessary to purge the propellant in these same line segments. First, the line segments of the docking interface are isolated and the vent valves are opened to vent the majority of the propellant. Then, similar to a leak check, the pressurant valves are opened and the pressure from the pressurant tanks forces the remaining propellant out into space. To mitigate the risk of combustion outside the vehicle, the fuel is purged alone first, and then after an orbit, the oxidizer is purged separately through a different vent valve on the opposite side of the port. Lastly, the lines are allowed to vacuum dry for a few minutes. Of course, if no propellant was transferred between the two vehicles at any time, such as on a Soyuz mission, then a propellant purge is not necessary.

\section{E. ISS Contamination}

While unsymmetrical dimethyl hydrazine (UDMH), monomethyl hydrazine (MMH), and nitrogen tetroxide (NTO) are all hazardous to human health, the general risks of crew or ISS atmosphere contamination from visiting 
vehicle thrusters are relatively minor. However, during an Extra Vehicular Activity (EVA), the crew can potentially be exposed to toxic propellants. Fuel and oxidizer reaction product (FORP), for instance, can accumulate, particularly near the thrusters, and not dissipate through sublimation or evaporation. Exposure to FORP is sometimes unavoidable if the EVA tasks require the crew to work near thrusters or propellant vents. Assuming the crew's suit does get contaminated, flight rules and procedures dictate that the crew frequently inspect and wipe down the suits and gloves in addition to stringent procedures for cleaning the suit when the crew has completed their tasks.

ISS contamination can also result from gross propellant leakage from propulsion system hardware in an EVA path. Contamination can be deposited on a spacesuit and then introduced into the ISS atmosphere by the EVA crew. While this concern is generally considered non-credible because most of the contamination evaporates rapidly, flight rules exist to protect against it and preventative procedures have been created due to the severity of the risks, should contamination of the internal environment occur. If the airlock does become contaminated, frozen propellant particles will evaporate readily under spacecraft cabin pressure conditions; and by subsequently exhausting and repressurizing, the contamination can be eliminated. This procedure clears the airlock of the contamination, adding a final level of safety to protect the crew before they re-enter the ISS.

ISS flight rules dictate Keep Out Zones (KOZ) to make sure the EVA crewmembers stay a safe distance away from the thrusters that could potentially leak or fire inadvertently. Experience with Space Shuttle and test programs studying propellants sprayed into vacuum have shown that small liquid leaks flash and vaporize almost instantly. Frozen or supercooled liquid is formed only with large, sustained leak rates greater than 150-300 grams/hour. It is, therefore, imperative for the visiting vehicles to show that the maximum undetectable propellant leakage will be less than 150 grams/hour ${ }^{13}$.

The flight rules also specify a minimum number of thruster inhibits required for crewmembers to be able to safely enter a defined KOZ. The KOZ for ATV thrusters, for instance, is specified as $1 \mathrm{~m}$ radius proximity and $60^{\circ}$ half angle cone downrange. If crewmembers have to get within the KOZ, a minimum of two mechanical inhibits each in fuel and oxidizer lines should be present. Two closed valves in series in each propellant line offer one fault tolerance against gross leakage and more than 2 fault tolerances against inadvertent firing, thus providing adequate mitigation against both critical (leakage) and catastrophic (firing) hazards. In addition to the mechanical inhibits, inadvertent thruster firing risk is mitigated by having three independent electrical inhibits.

If, for some reason, the required minimum mechanical inhibits cannot be in place and the EVA path requires the crewmember to enter a thruster KOZ, some workarounds maybe possible. For instance, leak checks will be mandated prior to EVA to demonstrate unambiguously that the thrusters will stay leak tight during EVA. Any undetectable leakage has to be less than 150 grams/hour, as described above. In addition to the leak check, visiting vehicles have to demonstrate, by way of Review of Design (ROD), that the thruster valves are fail safe (i.e., close when power is removed) and a positive upstream pressure helps them stay leak tight. The ROD must support the premise that there is no credible failure mode to cause leakage in a thruster that has been unused since its last good leak check, as long as it stays within its mechanical loads, thermal and aging limits. Once the leakage integrity is confirmed, the requirement on mechanical inhibits can be waived. However, the required number of electrical inhibits will still have to be in place. It may be noted that such workarounds are used only in exceptional cases, recognizing the fact that a lack of mechanical inhibits lowers the fault tolerances against potential hazards. Hence the requirement to demonstrate leakage integrity is quite stringent.

Similar approach can also be applied when thruster inhibits are specified for events such as robotic capture/release of a visiting vehicle, Mobile Transporter (MT) translation, etc. Inadvertent thruster firing, rather than leakage, is a concern for these tasks sensitive to structural loads. If it is not possible to have the required number of mechanical inhibits in place, in addition to the measures described above, visiting vehicles have to demonstrate that the maximum instantaneous thrust and total impulse generated by inadvertent firing of a single thruster would not exceed the allowable limit of the weakest structural member. For reference, a maximum instantaneous thrust of 0.13 $\mathrm{N}$ and total impulse resulting from leakage of trapped propellant volume of $600 \mathrm{cc}\left(6 \times 10^{-4} \mathrm{~m}^{3}\right)$ have been found acceptable in the past. Anything larger than this will have to be analyzed on a case by case basis.

\section{F. Departure and Abort Capability}

Departure, like approach and rendezvous, presents a number of challenges for the visiting vehicle propulsion systems. Departure from the ISS must be accomplished without damage to either the ISS or the visiting vehicle. In general, the ISS thrusters are inhibited just prior to departure in order to mitigate the risk of thruster firings during the first few critical moments after release or separation. Where necessary, the visiting vehicle may perform some departure readiness steps such as valve cycling, repriming, etc. prior to release. 
All visiting vehicles are required to have abort capability to protect against propulsion system failure or malfunction. This abort mode is programmed to take effect in a variety of scenarios, including but not limited to: an unsafe trajectory; loss of pressurization during regulated mode; thruster failure; or a delay in the departure burn regardless of the reason. This does put requirements upon the form and execution of a potential abort, which must be considered when designing the vehicle and the flight software.

A number of causes have the potential to result in a failed thruster. These causes include but are not limited to a thruster valve failing open or closed, the injector temperature exceeding or falling below temperature limits, or the chamber pressure exceeding or falling below the pressure limits required for thruster operation. If pressurant is ingested into the propellant, off-nominal thrust can result in a thruster being declared failed by the software. Several temperature or pressure sensors failing on the same thruster can result in a thruster failure. In addition to individual thruster failures, an entire set of thrusters can be declared failed. Generally this is due to one of the following causes: a thruster valve in the set is considered to be leaking propellant, the driver or power chain is failed, a failed ON thruster, or more than a predetermined number of thrusters in the set are declared failed. The flight rules define the critical failures and the course of action to be followed including the FDIR response.

The ISS Propulsion Team continues to monitor the health and status of the vehicle's propulsion system even after it leaves the ISS vicinity. For unmanned vehicles, the ISS Program has few flight rules regarding operation after this point, as the vehicle has no further potential for immediate impacts to the ISS except for flight articles that are returning as payload, and the continued monitoring is only used to gather further performance data for evaluation. The ISS Program monitors manned vehicles closely all the way through touchdown, as crew safety is paramount in any operation.

\section{Conclusion}

The ISS has proven to be the crown jewel of the international collaboration by establishing itself as a sophisticated orbiting laboratory to perform research that is increasingly benefiting humankind. The ISS is making a positive impact on the quality of life here on Earth. Continued operation of this cutting edge scientific research laboratory in an environment as harsh as Low Earth Orbit requires a significant effort to protect the safety of the crew and the integrity of the vehicles. Each Visiting Vehicle is able to meet all the ISS safety and mission requirements through their unique vehicle design. Sufficient margins are built into their design to account for worstcase on-orbit conditions. Based on a survey of best practices used across all vehicles, a 100 psid ( 0.7 MPa) propellant tank pressure on-orbit margin is considered appropriate for safe operation.

ISS Visiting vehicles have provided the bulk of the total ISS propellant consumption since the FGB was launched in 1998. With the exception of the propellant carried by the FGB and SM at launch, all of the nearly $80,000 \mathrm{~kg}$ of propellants came up with visiting vehicles. Using the requirements laid out in the SRD, IRD, and the flight rules, the ISS Program has successfully docked or berthed visiting vehicles over one hundred and twenty times throughout the fourteen years of its life, so far.

A united effort on the part of all international and commercial partners in the design and operation of visiting vehicles is vital to the continued life of the ISS. Success of the ISS has been possible largely with the propulsive support of visiting vehicle thrusters and the thousands of kilograms of propellant, life-sustaining supplies and hardware, and crew members carried into orbit each year by visiting vehicles. Assuming the ISS continues to operate until 2028, the next sixteen years require continued flights to support its operation.

The system is not without flaws, and problems have indeed arisen with vehicle traffic. However, the Program has successfully proven itself to be able to operate with a high degree of success, and the process of visiting vehicle propulsion system design and integration promises to enable the Program to continue that success into the future.

\section{Appendix: Acronyms}

$\begin{array}{ll}\text { ATV } & =\text { Automated Transfer Vehicle } \\ \text { BTI } & =\text { Burn-Time Integration } \\ \text { DC-1 } & =\text { Docking Compartment } 1 \\ \text { DFMR } & =\text { Design for Minimum Risk } \\ \text { ESA } & =\text { European Space Agency } \\ E V A & =\text { Extra-Vehicular Activity } \\ \text { FDIR } & =\text { Fault Detection Isolation and Recovery } \\ \text { FGB } & =\text { Functional Cargo Block (Russian Acronym) }\end{array}$




$\begin{array}{ll}\text { FORP } & =\text { Fuel Oxidizer Reaction Products } \\ H T V & =\text { H-II Transfer Vehicle } \\ I R D & =\text { Interface Requirements Document } \\ \text { ISS } & =\text { International Space Station } \\ J A X A & =\text { Japan Aerospace Exploration Agency } \\ K O S & =\text { Keep-Out Sphere } \\ K O Z & =\text { Keep-Out Zone } \\ M E O P & =\text { Maximum Expected Operating Pressure } \\ M D P & =\text { Maximum Design Pressure } \\ M L M & =\text { Multipurpose Laboratory Module } \\ M M H & =\text { Monomethylhydrazine } \\ M R M & =\text { Mini Research Module } \\ N A S A & =\text { National Aeronautics and Space Administration } \\ N T O & =\text { Nitrogen Tetroxide } \\ O M S & =\text { Orbital Maneuvering System } \\ P V T & =\text { Pressure-Volume-Temperature } \\ R C S & =\text { Reaction Control System } \\ R F S & =\text { Refueling System } \\ R S M C S & =\text { Russian Segment Motion Control System } \\ S E \& I & =\text { Systems Engineering and Integration } \\ S M & =\text { Service Module } \\ S R D & =\text { Safety Requirements Document } \\ S S R M S & =\text { Space Station Remote Manipulator System } \\ U D M H & =\text { Unsymmetrical dimethylhydrazine } \\ U S T O & =\text { US Thrusters Only } \\ V I P e R & =\text { Vehicle Integrated Performance and Resources }\end{array}$

\section{References}

\footnotetext{
1 “Interface Definition Document (IDD) for International Space Station (ISS) Visiting Vehicles (VVs)”, NASA, SSP 50235, Houston, TX, Feb. 2000.

${ }^{2}$ Karakulko, W., Russell, S., Sanders, G.B., Spencer, V., "Russian Propulsion and Propellant Resupply Systems for the ISS”, NASA, JSC-27979 Rev. F, Houston, TX, Mar. 2010.

${ }^{3}$ Kamath, U.P., Krajchovich, M.C., Swanson, R.A., “ATV Propulsion and Propellant Resupply Systems Databook”, The Boeing Company, Publication No. D684-13250-01, Houston, TX, Jan. 2009.

${ }^{4}$ Beisner, M., Kamath, U.P., Swanson, R.A., "HTV Propulsion Systems Databook”, The Boeing Company, Publication No. D684-13625-01 Rev A, Houston, TX, Mar. 2011.

5 "International Space Station (ISS) to Commercial Orbital Transportation Services (COTS) Interface Requirements Document (IRD)”, NASA, SSP 50808, Houston, TX, July 2007.

6 “Safety Requirements Document (SRD)”, NASA, SSP 50021 DCN 004, Houston, TX, July 2009.

${ }^{7}$ Yamamoto, M., Nakai, S., Ishizaki, S., Matsuo, S., Imada, T., Russell, S., and Kamath, U.,"Surge Pressure Management in HTV Propulsion System,” 43rd AIAA/ASME/SAE/ASEE Joint Propulsion Conference \& Exhibit, Cincinnati, OH, July 2007.

${ }^{8}$ Cross, A., Duffin, S., and Greenberg, Z. "Transient Surge Pressure Characterization of a Spacecraft Propulsion Subsystem due to Propellant Priming and Thruster Valve Cycling”, JANNAF, JANNAF 2012-0001I, San Antonio, TX, May 2012.

9 “Structural Design and Verification Requirements”, NASA, SSP 30559 Rev D, Houston, TX, July 2007.

10 “Space Systems - Composite Overwrapped Pressure Vessels (COPVs)”, ANSI/AIAA, S-081A-2006, Reston, VA, July 2006.

${ }^{11}$ Keyser, L., “Apollo Experience Report - the Role of Flight Mission Rules in Mission Preparation and Conduct”, NASA TN D-7822, Houston, TX, Nov. 1974.

${ }^{12}$ Kamath, U., Metrocavage, K., Russell, S., Spencer, V., Swanson, R.A., “On-Orbit Propulsion and Methods of Momentum Management for the International Space Station”, AIAA, AIAA 2009-4899, Denver, CO, Aug. 2009.

${ }^{13}$ Pedley, M.D., Internal Note to NASA EVA Project Office, "Propellant Contamination Issues - Potential Hazards to Crew", NASA, Houston, TX, Feb. 2001.
} 


\section{On-Orbit Propulsion System Performance of ISS Visiting Vehicles}

Mary Regina Martin, Robert A. Swanson, and Ulhas P. Kamath The Boeing Company, Houston, TX 77059

Francisco J. Hernandez and Victor Spencer NASA Lyndon B. Johnson Space Center, Houston, TX 77058 
- Abstract

- ISS Visiting Vehicles

- Propulsion System Requirements and Priorities

- Hazard Control

- Design Drivers for Pressure Systems

- Integration and Operations

- Conclusion

- Sources 


\section{Abstract}

- ISS represents the culmination of over two decades of unprecedented global human endeavors to conceive, design, build and operate a research laboratory in space.

- Uninterrupted human presence in space has been made possible by an international fleet of space vehicles facilitating crew rotation, delivery of science experiments and replenishment of propellants and supplies.

- On-orbit propulsion systems on both ISS and Visiting Vehicles are essential to the continuous operation of the ISS.

- This paper compares the ISS visiting vehicle propulsion systems by providing an overview of key design drivers, operational considerations and performance characteristics.

- Despite their differences in design, functionality, and purpose, all visiting vehicles must adhere to a common set of interface requirements along with safety and operational requirements.

- This paper addresses a wide variety of methods for satisfying these requirements and mitigating credible hazards anticipated during the on-orbit life of propulsion systems, as well as the seamless integration necessary for the continued operation of the ISS. 


\section{ISS Visiting Vehicles}

Visiting Vehicles provide the ISS with its necessary lifeblood of cargo and consumables, including propellants.

- 7 sets of Visiting Vehicles to date:

- Soyuz

- Space Shuttle Orbiters

- Progress

- ATV

- HTV

- Dragon

- Future Vehicles

- Cygnus (scheduled to fly Summer 2013)

- Commercial Crew vehicles ( 2017) 


\section{ISS Visiting Vehicles}

ISS Visiting Vehicle Flights

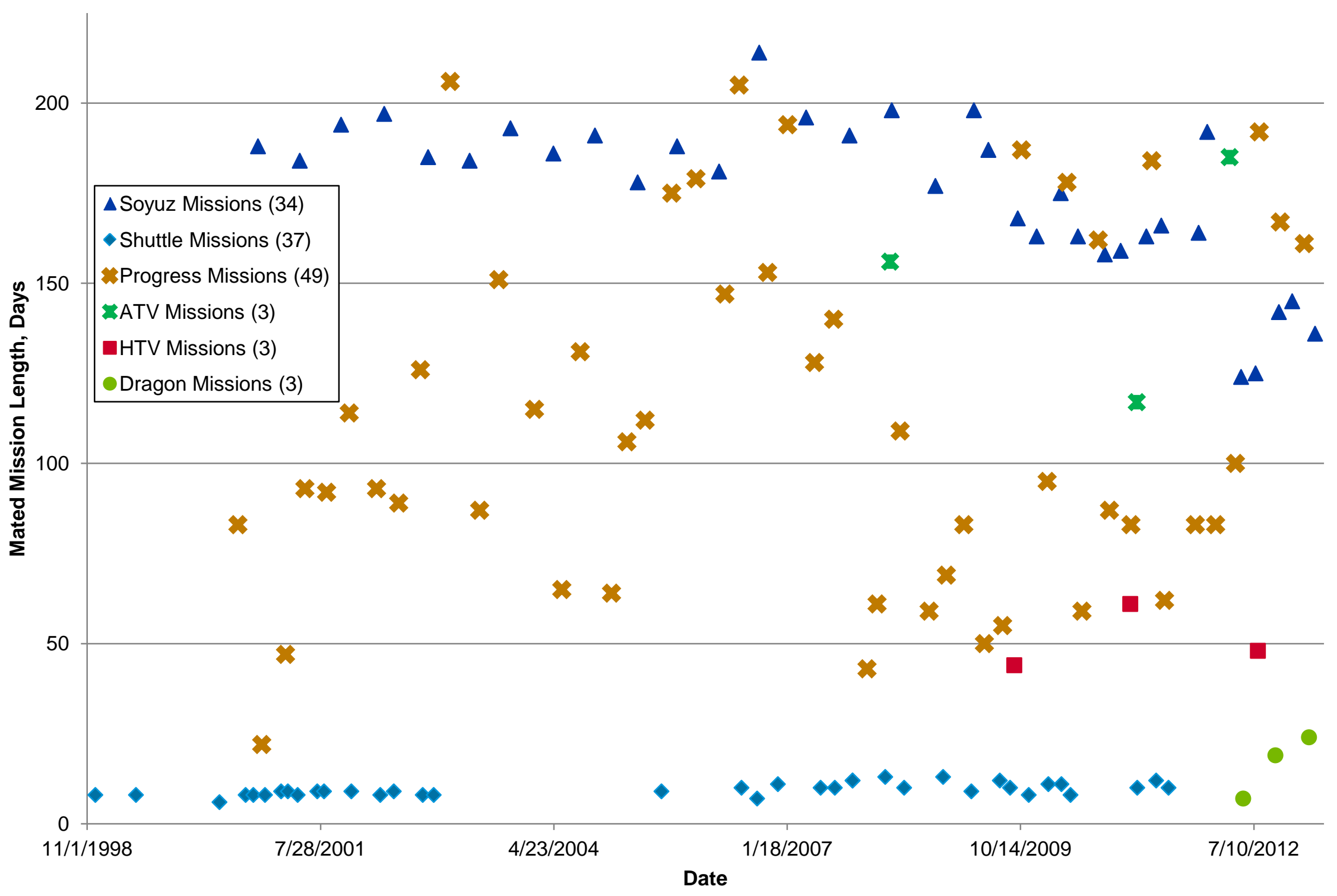




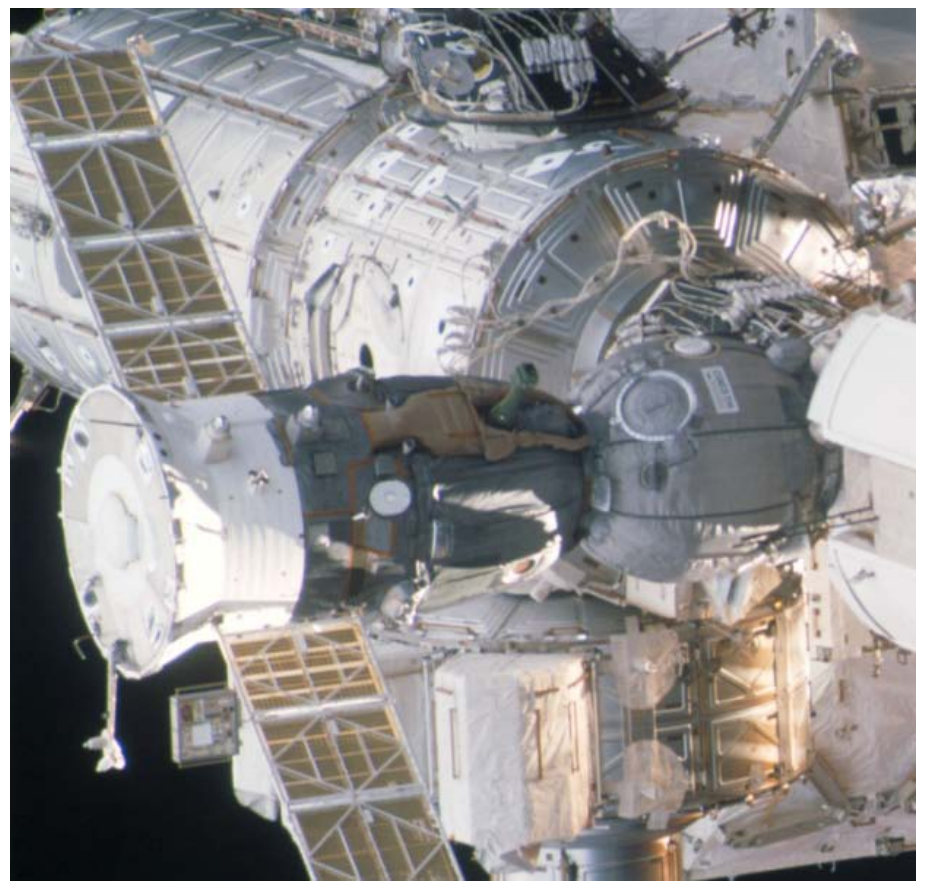

- Primary (current) crew vehicle flying to the ISS.

- Can provide propulsive control to ISS in off-nominal cases

- Docks autonomously using its own propulsion system

- Flown 34 ISS Missions

- Propellant: UDMH and NTO

- Pressurant: Helium 


\section{Orbiter (Space Shuttle)}

- Primary US crew vehicle until retired

- Provided propulsive support during mated missions

- Docked autonomously using its own propulsion system

- Flown 37 ISS Missions

- Propellant (OMS and RCS): $\mathrm{MMH}$ and NTO

- Pressurant: Helium

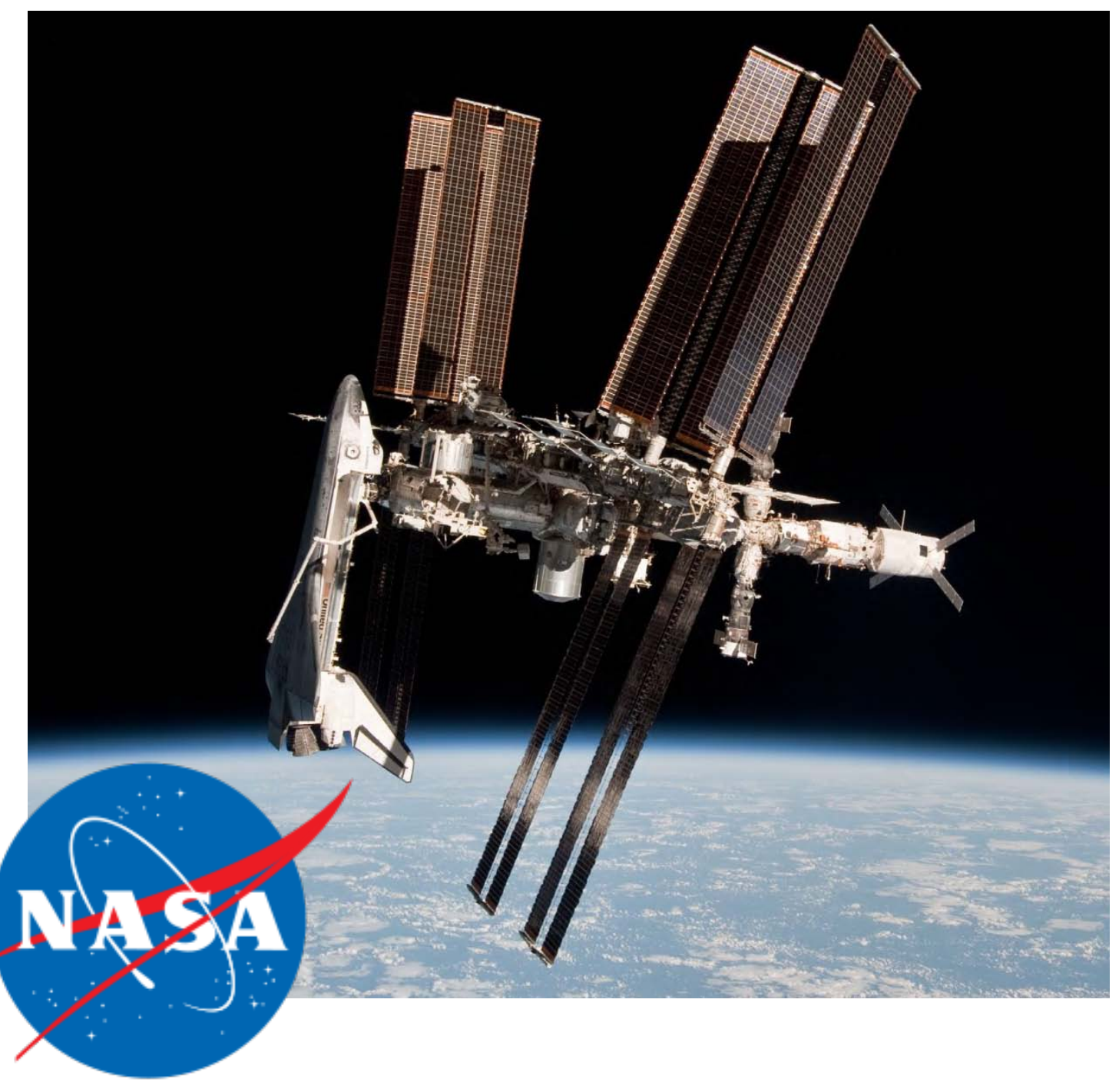




\section{Progress}

- Primary current cargo vehicle

- Provides propellant refueling support

- Provides propulsive support, including primary ISS roll control capability until docking of the MLM

- Docked autonomously using its own propulsion system

- Flown 49 ISS Missions

- Propellant: UDMH and NTO

- Pressurant: Helium (CPS) and Nitrogen(RFS)

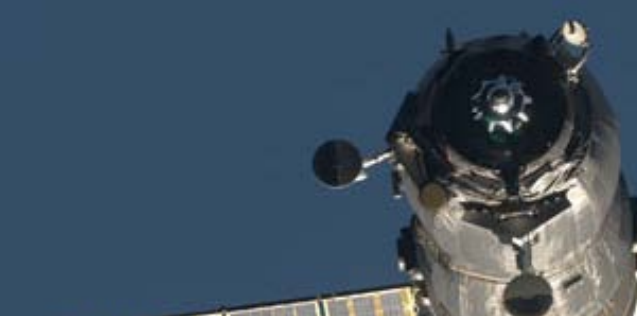




\section{Automated Transfer Vehicle (ATV)}

- High capacity cargo vehicle

- Provides propellant resupply support

- Provides propulsive support

- Docked autonomously using its own propulsion system

- Flown 3 ISS Missions

- Propellant: MMH (PRSS), UDMH (RFS), and NTO

- Pressurant: Helium

\section{esa}

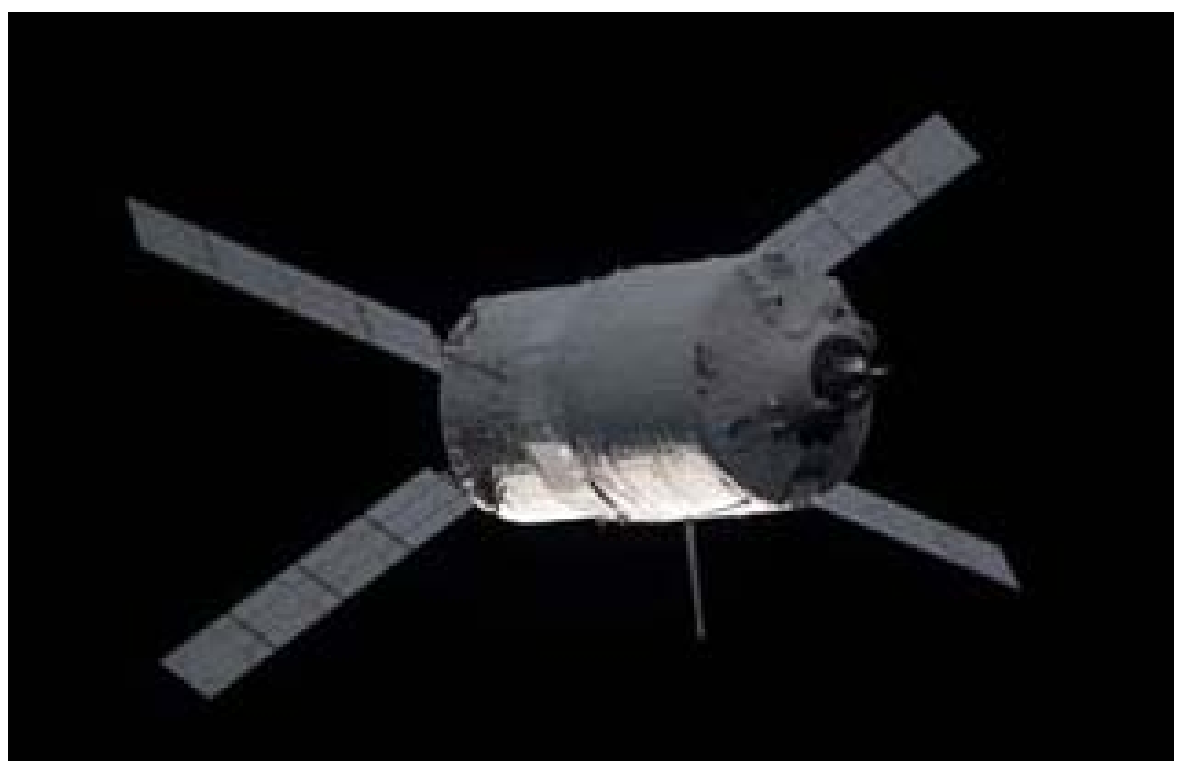




\section{H-II Transfer Vëhicle (HTV)}

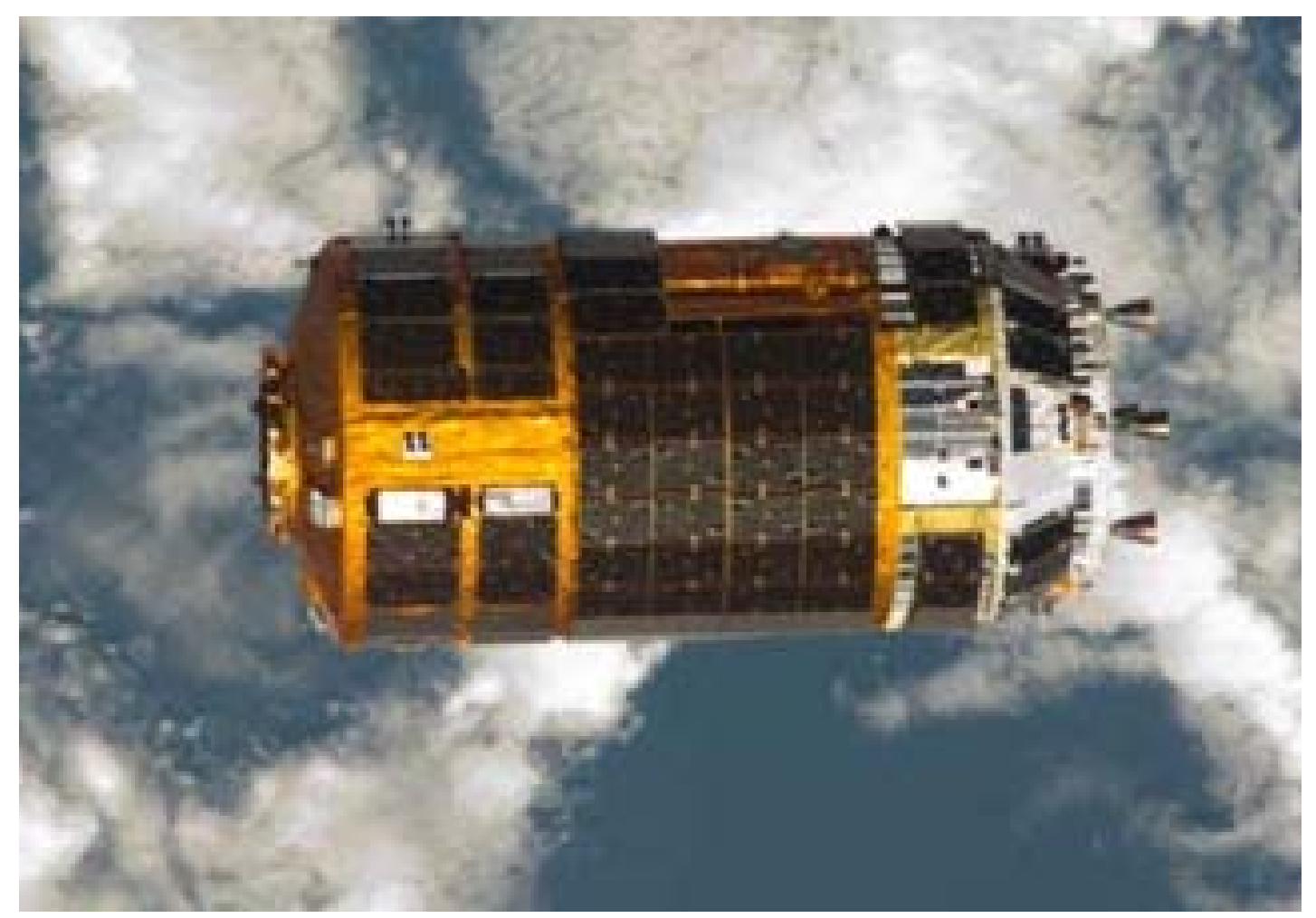

- Large capacity cargo vehicle

- Mates to the ISS Node 2 port via a capture and berthing method

- Flown 3 ISS Missions

- Propellant: $\mathrm{MMH}$ and MON3

- Pressurant: Helium 


\section{Dragon}

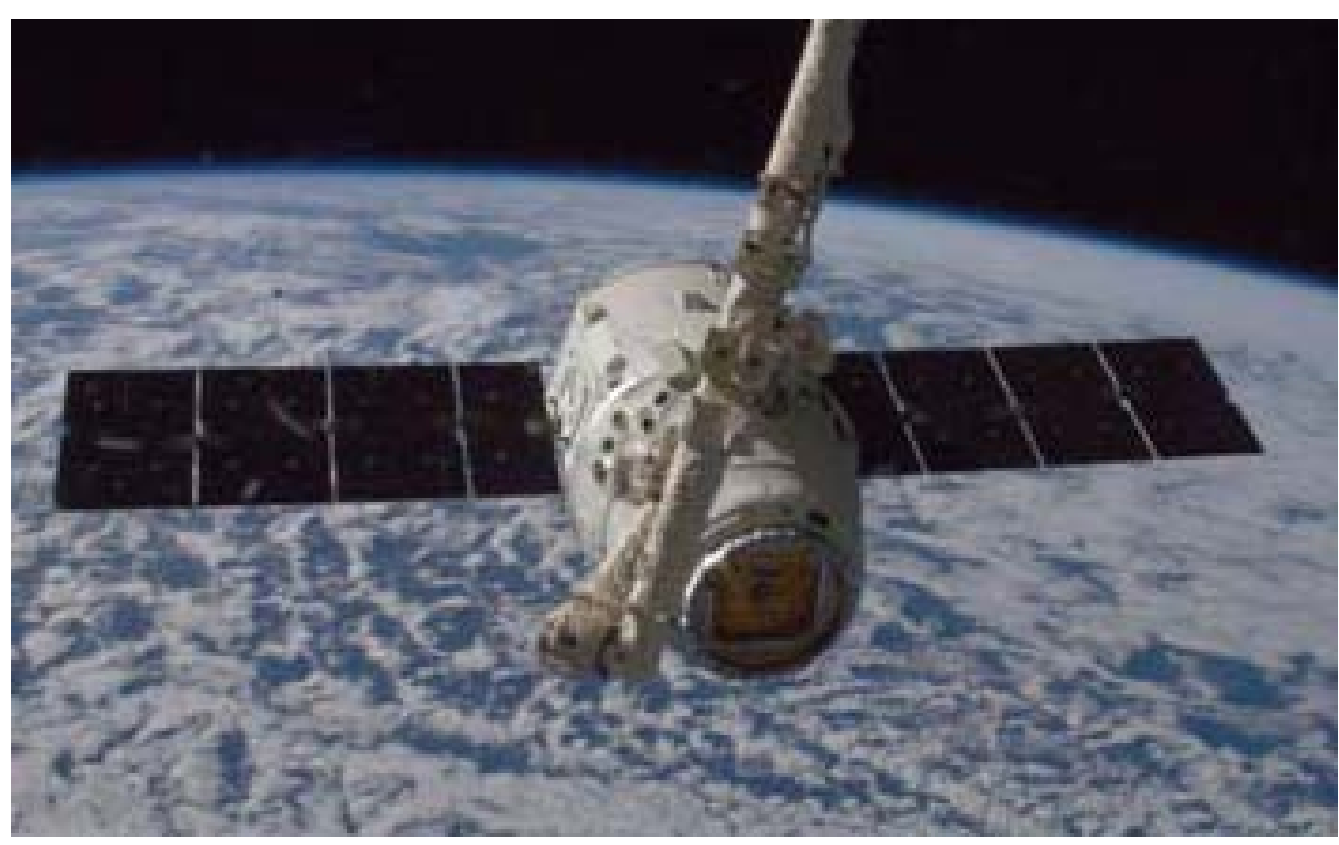

- Commercially-developed US cargo vehicle

- Mates to the ISS Node 2 port via a capture and berthing method

- Only current returnable cargo vehicle

- Flown 3 ISS Missions

- Propellant: MMH and NTO

- Pressurant: Helium

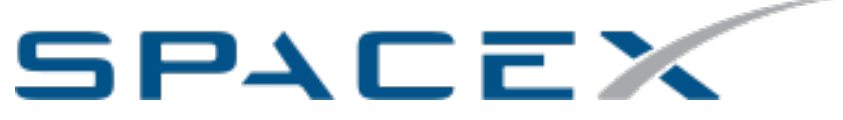




\section{Cygnus}

- Commerciallydeveloped US cargo vehicle

- Mates to the ISS Node 2 port via a capture and berthing method

- $1^{\text {st }}$ ISS Mission scheduled for Summer 2013

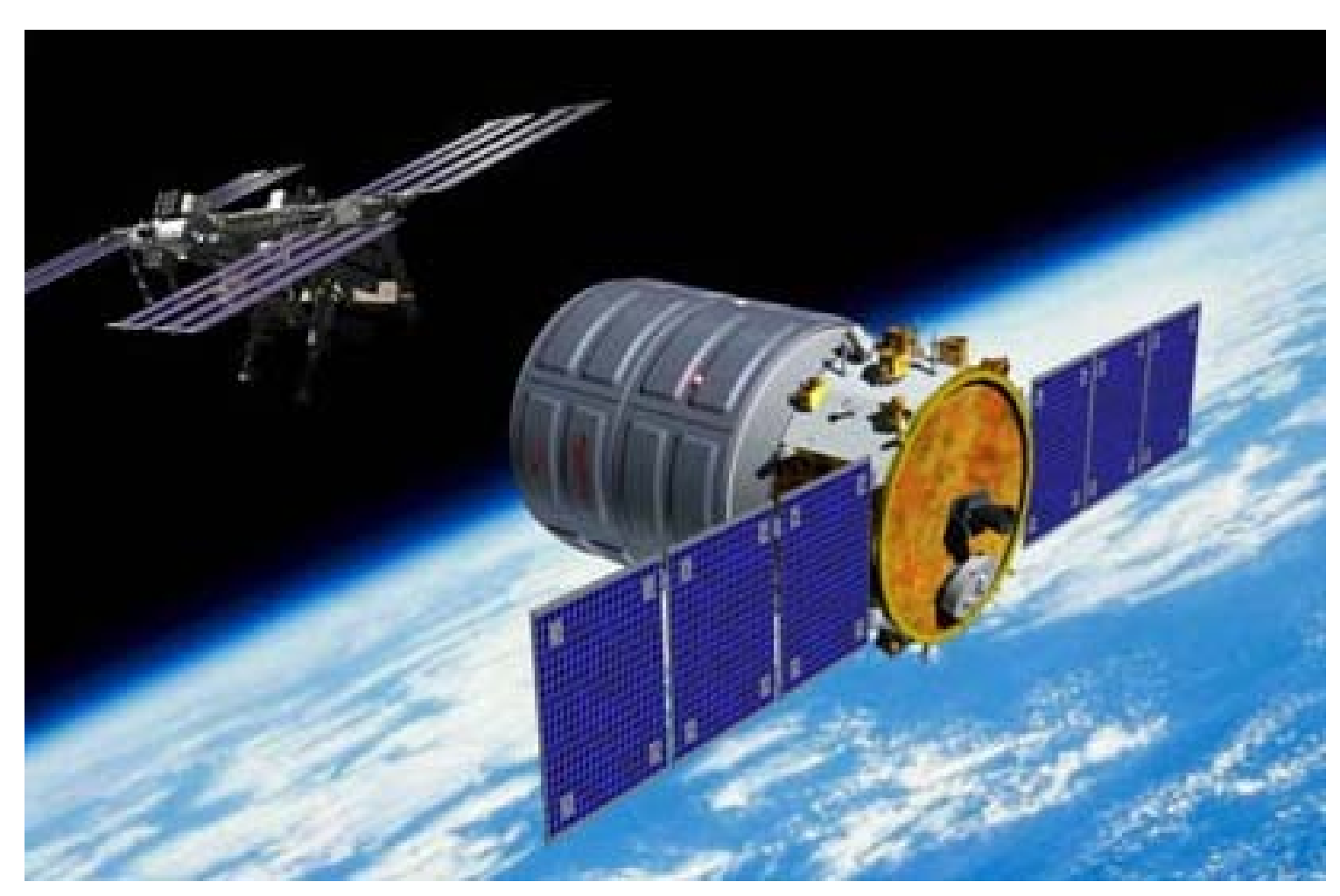

- Propellant:

Hydrazine and NTO 


\section{Future Vehicles}

- Future commercial crew vehicles are under development under the Commercial Crew Integrated Capacity (CCiCAP) contract and Certification Product Contract (CPC).
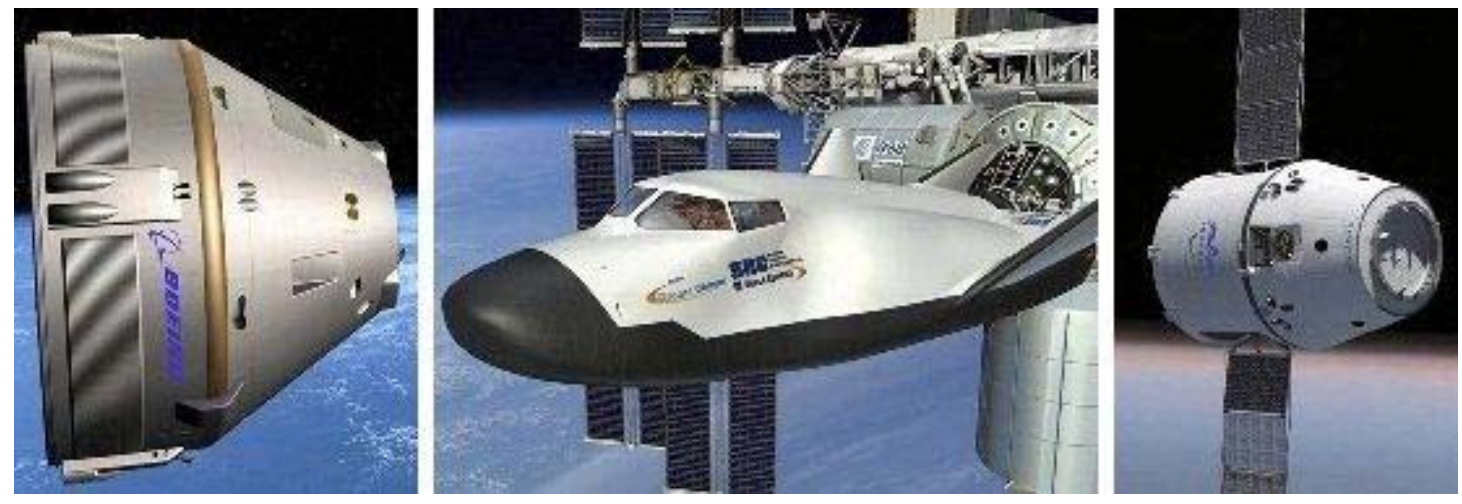


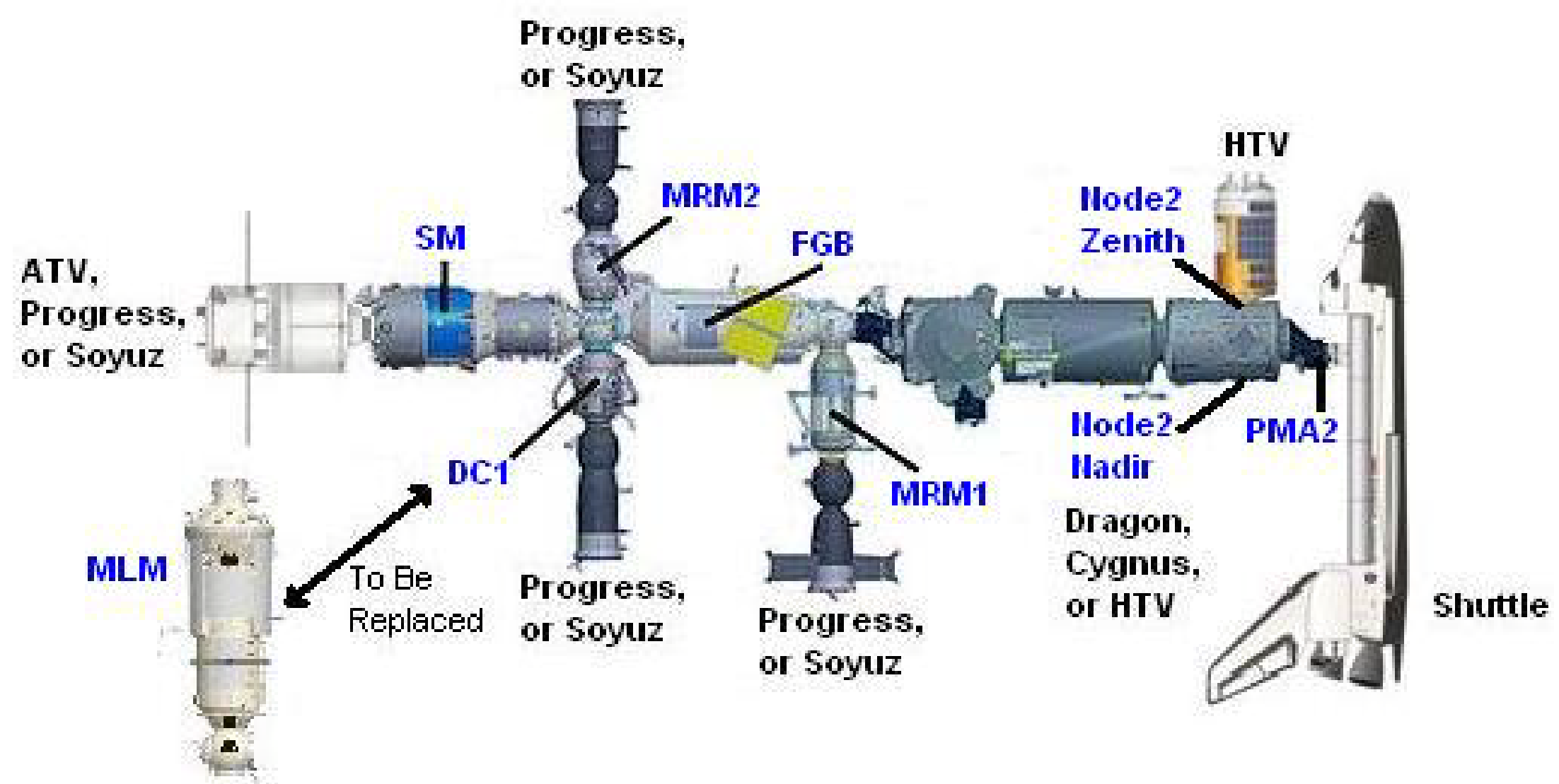




\section{Visiting Vehicle Priorities}

1.Crew Safety

2. ISS safety

3. Protection of ISS lifetime

4. Protection of ISS docking and berthing capability

5. Visiting Vehicle safety

6. Mission success 


\section{Propulsion System Requirements}

- Design and Operations driven by:

- ISS Program requirements and constraints

- International agreements

- Mission goals

- Visiting Vehicle intended purpose

- Safety of crew and ISS structure

- All Visiting Vehicles must meet:

- Safety Requirements Document (SRD)

- Interface Requirements Documents (IRDs)

- Segment Specifications

- All ISS Flight Rules 


\section{Sample Propulsion System Design}
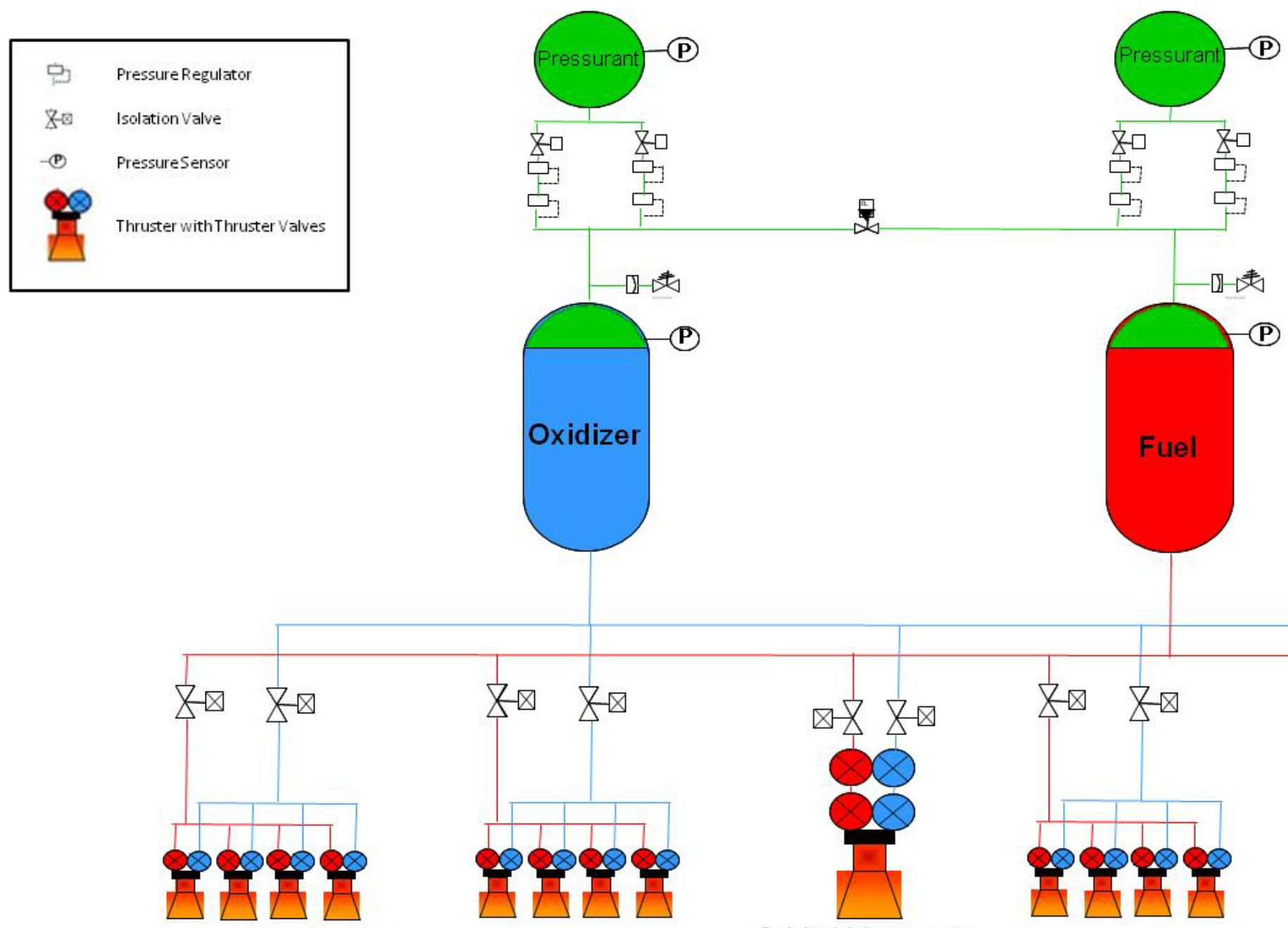

Reaction Control System (RCS)

Orbital Maneuver

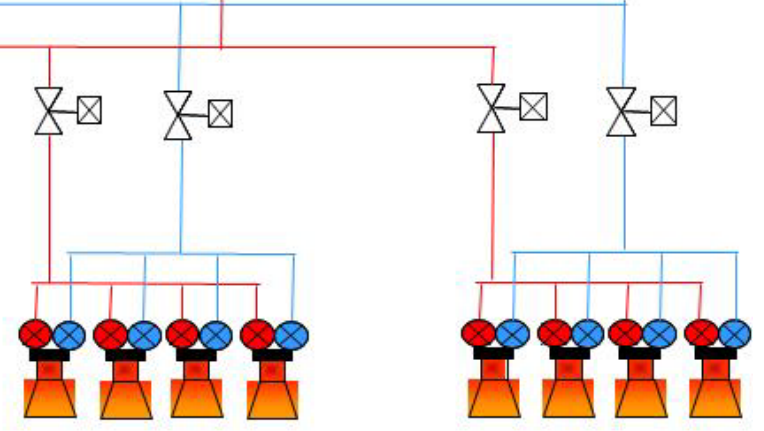

Engine 


\section{Hazard Control}

- Hazard Control - the use of design and operational measures to reduce the likelihood of hazardous effects

- Hazard Control includes:

- Hazard Elimination

- Damage Control

- Containment

- Isolation of potential hazards

- Failure tolerance considerations

- Incorporation of safety devices

- Crew operational procedures

- Protective clothing and equipment 
- Most common propulsion system hazards:

- Collision

- Contamination

- Explosion

- Two categories of hazards:

- Catastrophic - hazard resulting in disabling or fatal crew injury, or loss of ISS or Orbiter

- Critical - hazard resulting in non-disabling crew injury, severe occupational illness, loss of a major ISS life-sustaining element, or damage to the Orbiter or ground facility 


\section{Hażard Control}

- Methods of meeting safety requirements:

- Fault tolerance (preferred and sometimes mandated)

- Design for minimum risk

- Isolation

- Operational control

- Fault Tolerance:

- Catastrophic Hazards: require two fault tolerance or three independent inhibits

- Critical hazard: require single fault tolerance or two independent inhibits 


\section{$-\infty$

- Water Hammer/Surge Pressure

- Maximum Design Pressure (MDP)

- Highest pressure driven by maximum pressures of propulsion system components, maximum temperature, and transient temperature excursions

- Accommodates two worst case failures

- Maximum Expected Operating Pressure (MEOP)

- Maximum pressure at which system operates in nominal conditions.

- MDP must have sufficient margin above MEOP

- Over-Pressurization Protections

- Primary Regulator Set Point 


\section{Pressure System Parameters}

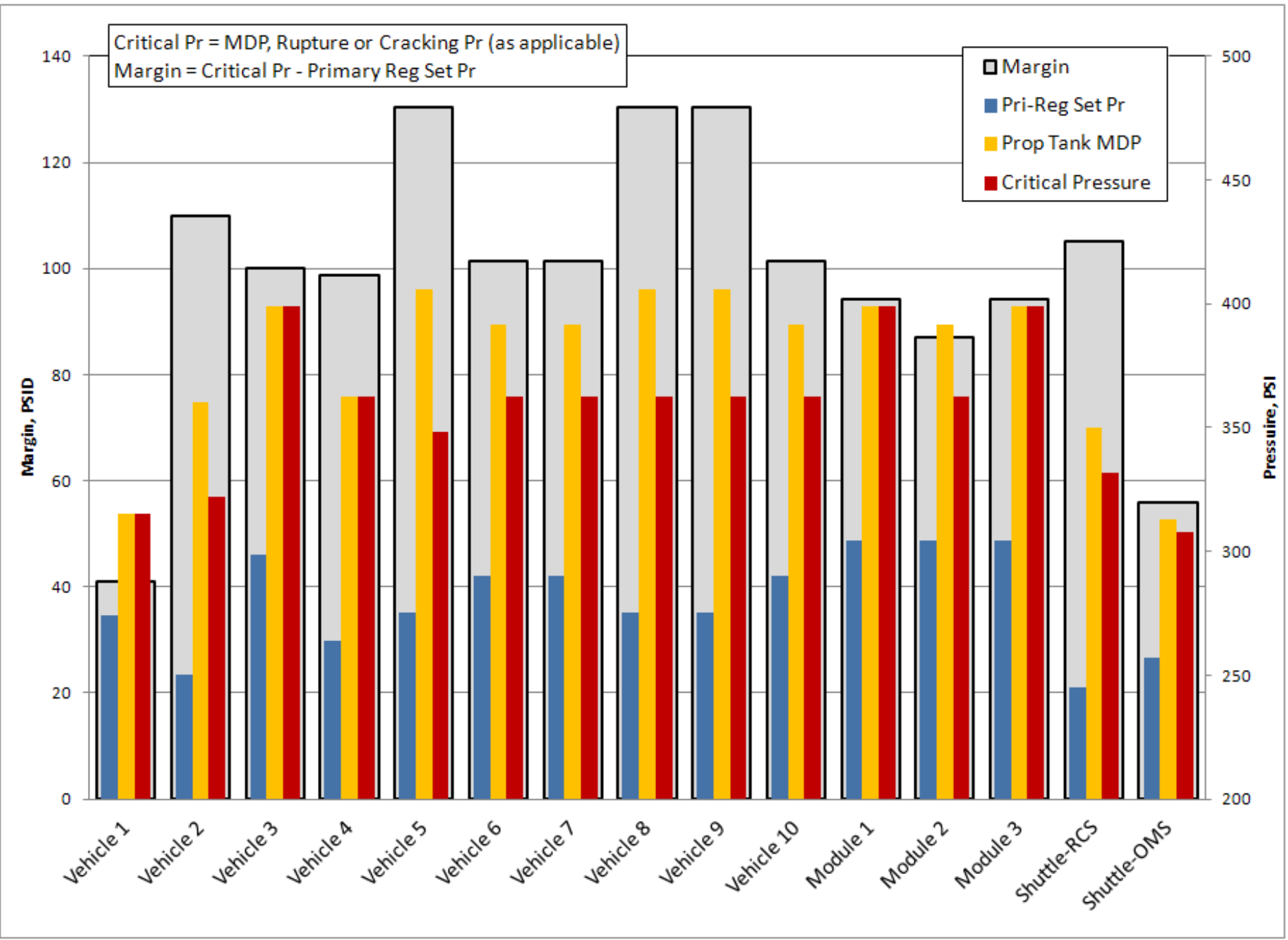




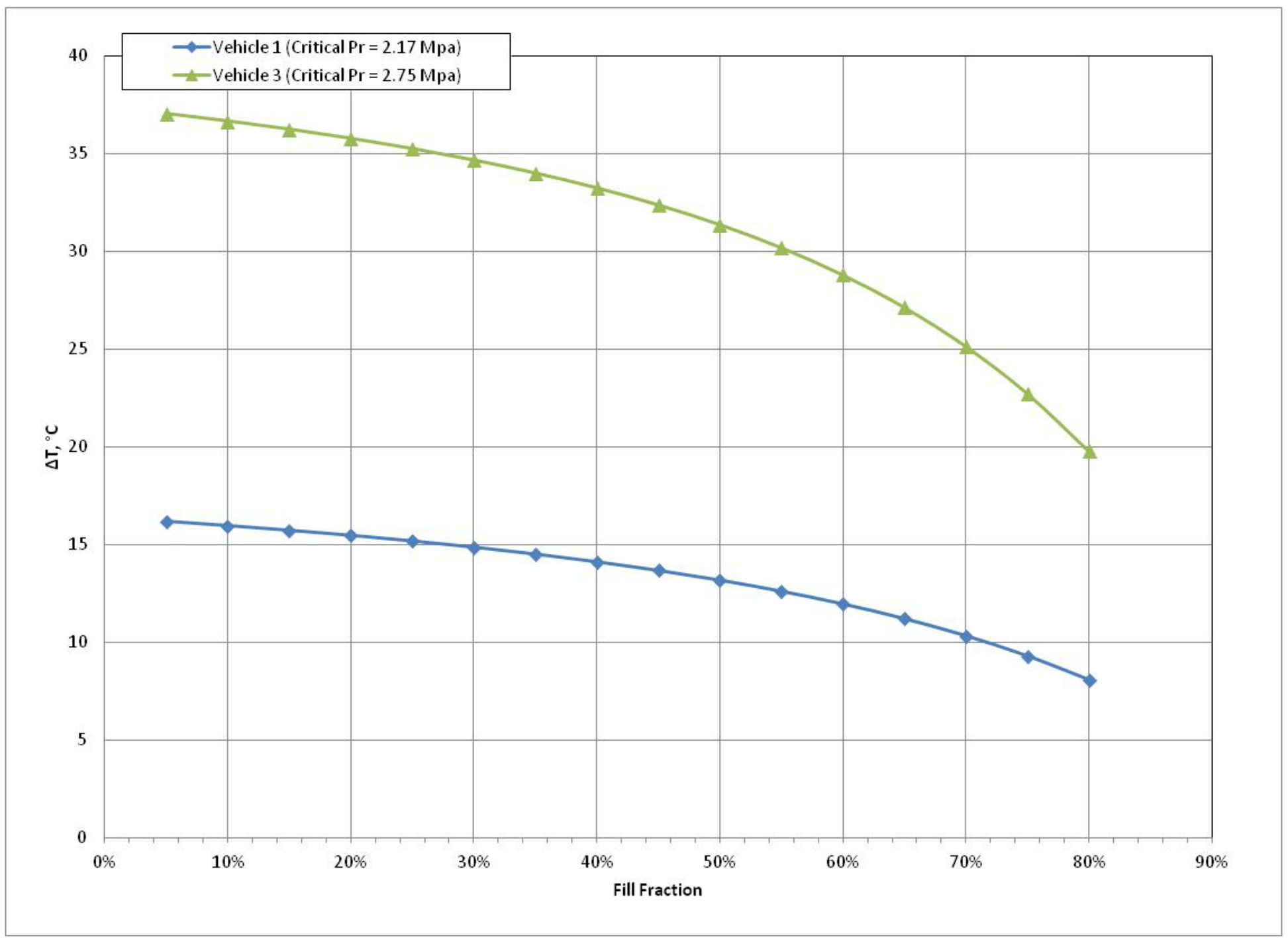


- Flight rules:

- Developed in a joint effort by MOD, ISS engineering specialists, and vehicle owners

- Integrate relevant engineering constraints

- Outline procedures for nominal mission operations

- Assign responsibility and authority

- Plan a course of action for potential contingencies and anomalies 


\section{Propellant Quantity Gauging}

- 4 primary propellant quantity gauging methods

- PVT method

- Uses ideal gas law

$$
P V=n R T
$$

- BTI method

- $m=$ consumption in $\mathrm{kg}$

- $F=$ thrust in $\mathrm{kg}_{\mathrm{f}}$

- $T_{\text {on }}=$ total on-time in seconds

$$
\begin{aligned}
& m=F^{*} T_{\text {or }} / I_{s p} \\
& F=\left(K 1{ }^{*} P_{\text {avg }}\right)+K 2
\end{aligned}
$$

- $I_{s p}=$ specific impulse

- $P_{\text {avg }}=$ the average pressure of all tanks feeding the thruster in $\mathrm{kg} / \mathrm{cm}^{2}$

- $K 1$ and $K 2=$ constants derived from the acceptance test data for each type of thruster

- Radio frequency method

- Physical measuring device utilizing properties of diaphragm tanks 


\section{Integration and Operations}

- System priming

- Flight in regulated vs blowdown mode

- Thruster failure detection and reaction

- Docking vs Capture and Berthing

- Thruster inhibits during docked or berthed phase

- Propulsive support - attitude control and translation

- Russian Control

- USTO

- Loads and structural concerns

- Propellant resupply

- ISS atmosphere contamination

- Abort capability 


\section{ISS Propulsive Support}

- Commanded by Service Module computers

- 2 modes:

- Russian Segment Motion Control System (RS MCS)

- US - Thrusters Only (USTO)

- Roll Attitude Control

- Service Module

- Progress at DC-1 Nadir or MRM2 Zenith

- MLM (scheduled for launch in Dec 2013)

- Pitch/Yaw Attitude Control

- Service Module

- Progress at SM-Aft

- ATV at SM-Aft 


\section{ISS Propulsive Support}

- Significant portion of ISS thruster control is dedicated to translational control (mostly reboosts)

- Translational control

- Progress R\&D thrusters at SM-Aft

- ATV thrusters (OCS or ACS) at SM-Aft

- SM Main Engines

- Progress Mid-Ring thrusters at DC-1 Nadir

$$
\text { ( } \Delta \mathrm{V} \leq 0.7 \mathrm{~m} / \mathrm{s} \text { only })
$$




\section{Aliss Mean Altitude vs. Accumulated $\Delta \mathbf{V}$}

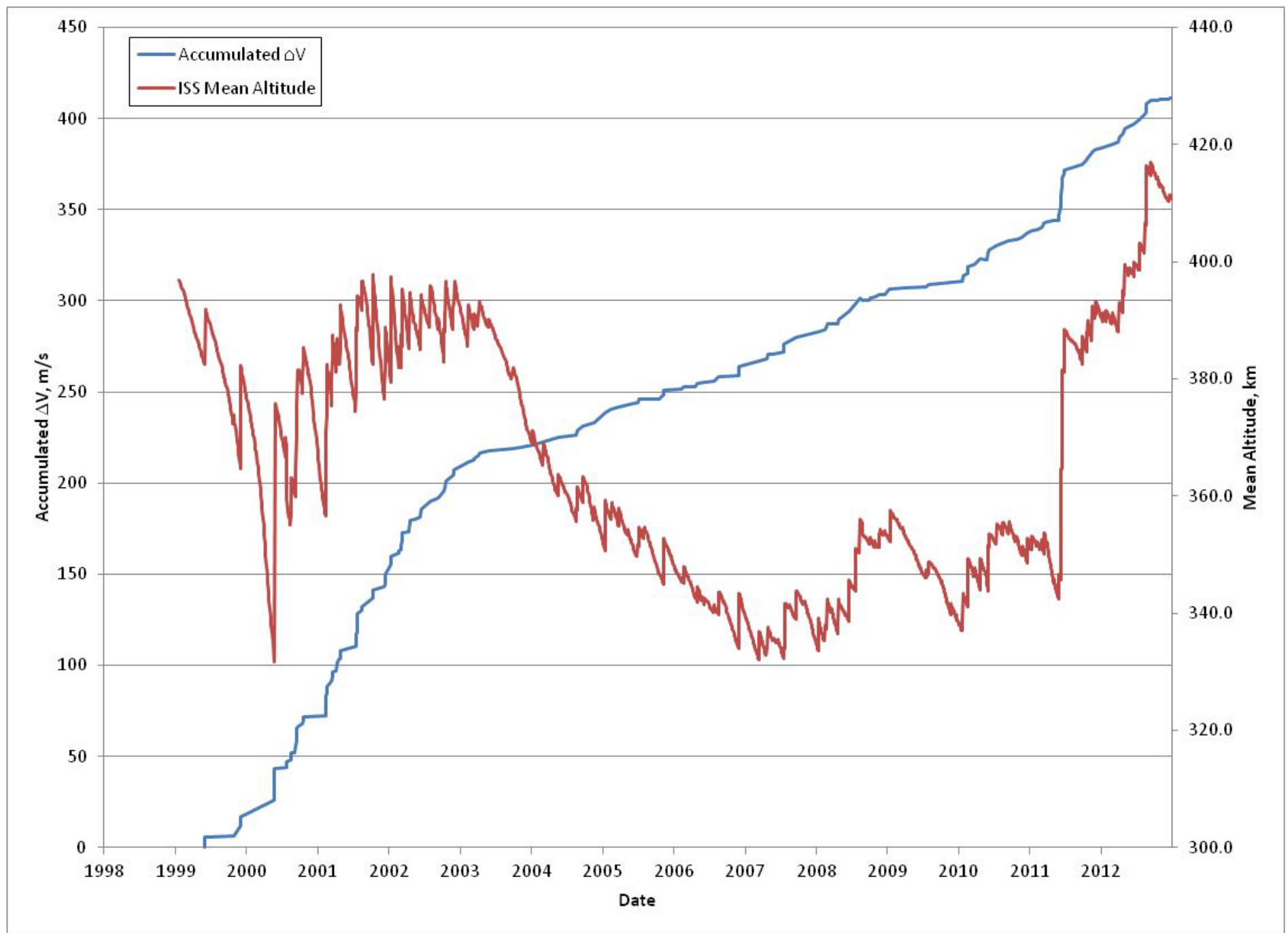




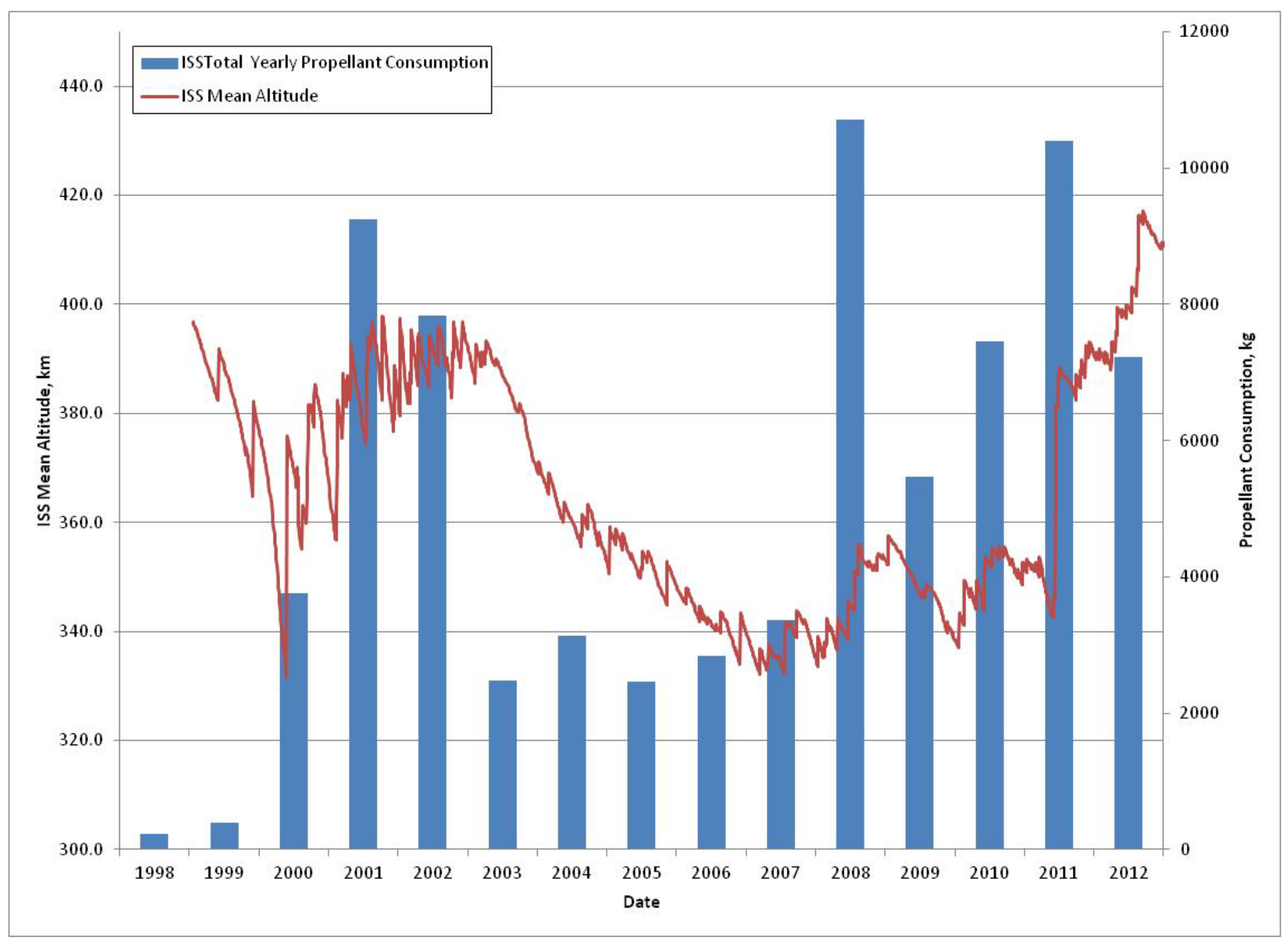




\section{ISS Refueling Support}

- ISS Total On-Orbit Propellant Capacity $=\mathbf{7 4 6 0} \mathbf{~ k g}$

- Maximum Propellant Capacity of FGB $=6600 \mathrm{~kg}$

- Maximum Propellant Capacity of SM $=860 \mathrm{~kg}$

- Total Propellant consumed over ISS Program: nearly $80,000 \mathrm{~kg}$

- Propellant provided by Visiting Vehicles:

$\sim 75,000 \mathrm{~kg}$ 


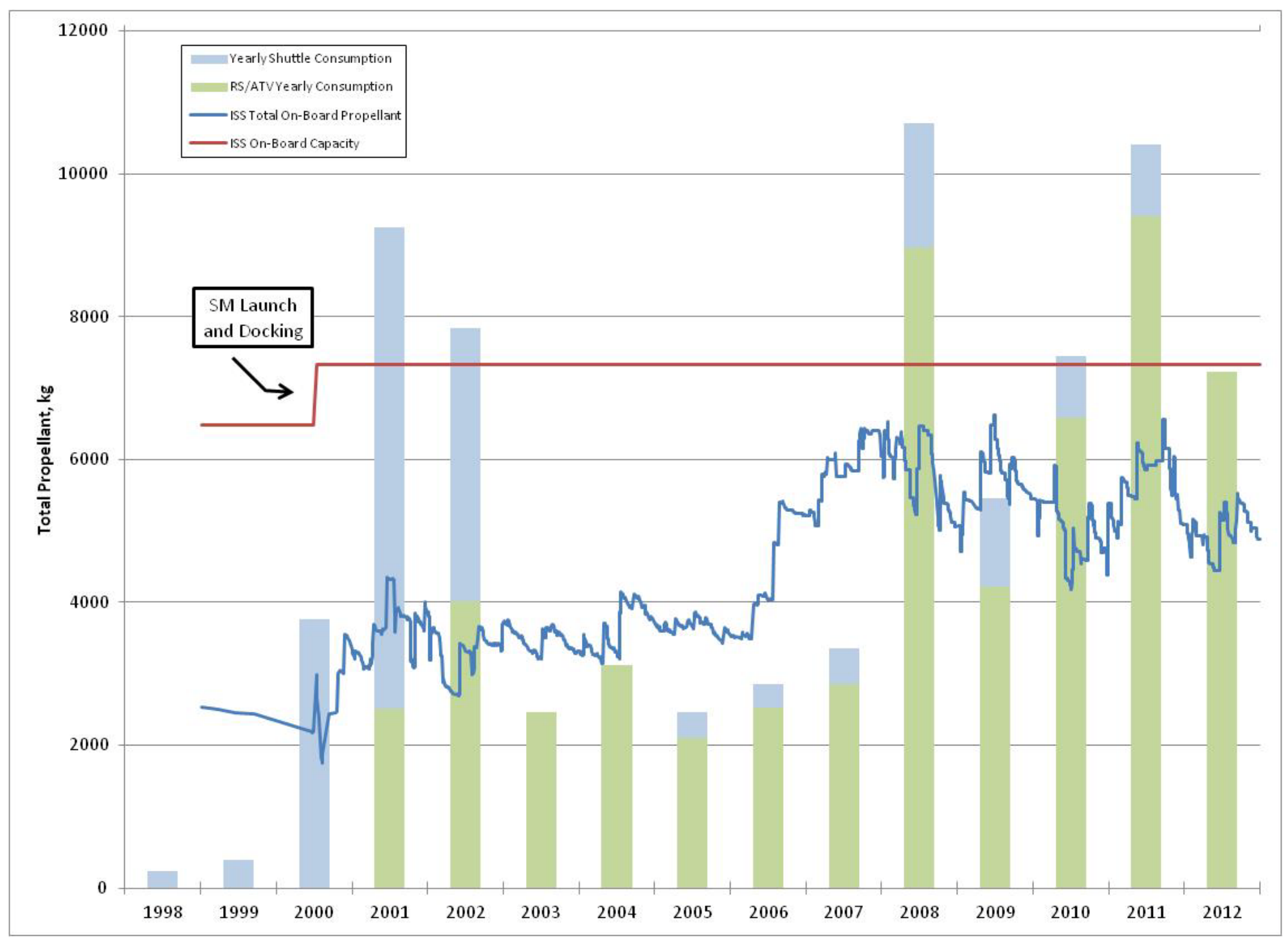




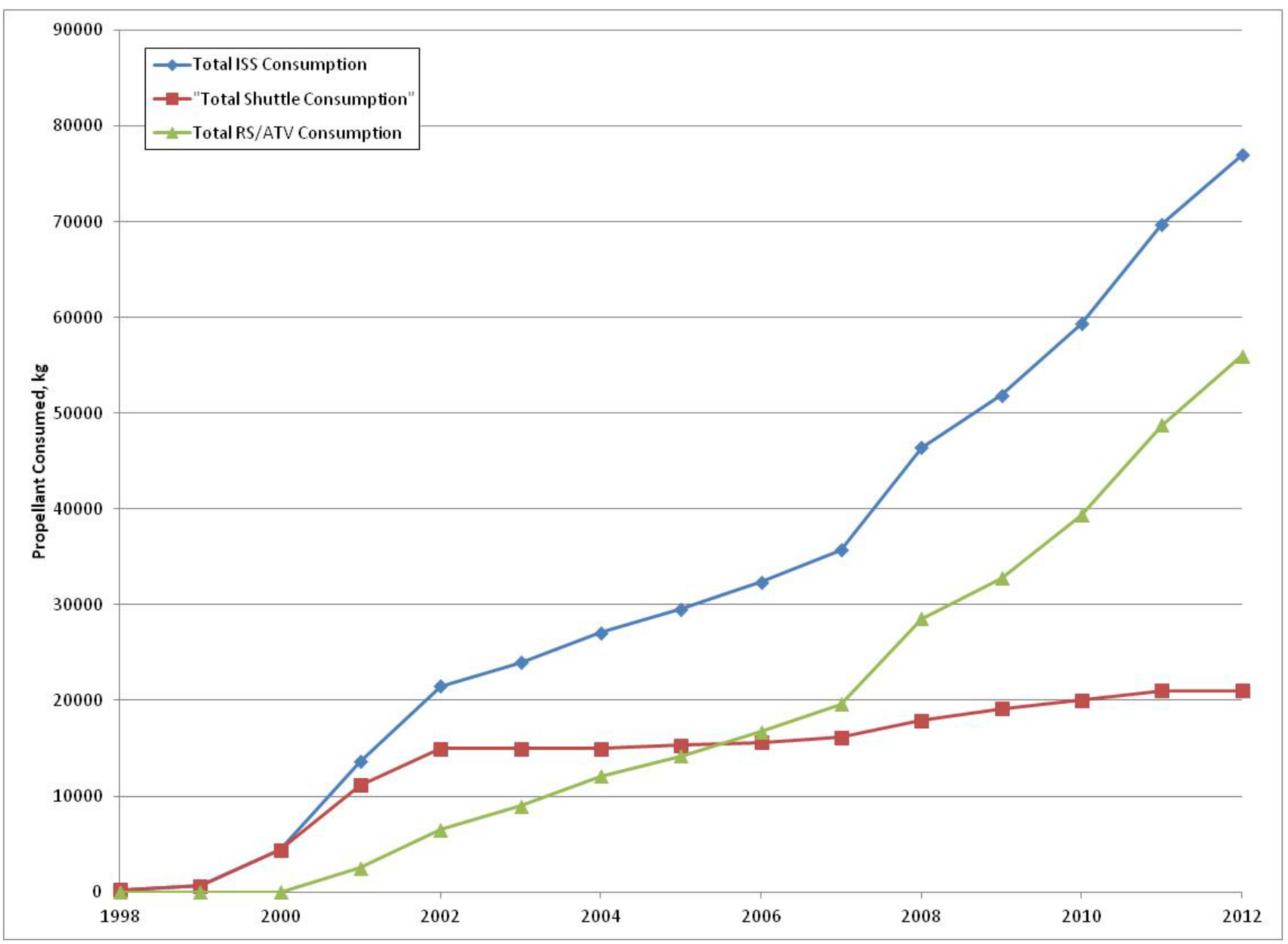




\section{ISS Contamination}

- General crew or atmosphere contamination risks are relatively minor except during EVAs

- EVA contamination risks:

- Fuel and Oxidizer Reaction Product (FORP)

- Gross propellant leakage

- Contamination deposited on a spacesuit

- Protections in place:

- Procedures to wipe down suits during EVA

- Procedures to clean suits after EVA

- Procedure to eliminate contamination in airlock

- Keep Out Zones (KOZ) in vicinity of thrusters

- Vehicles must show maximum undetectable propellant leakage is $<150$ grams/hour

- Thruster inhibits request for crew to enter KOZ

- Some workarounds available if minimum \# of inhibits is not possible 
- Abort capability necessary to protect against propulsion system failure or malfunction:

- Unsafe trajectory

- Loss of pressurization during regulated mode

- Thrusters failures

- Delay in departure burn

- Etc.

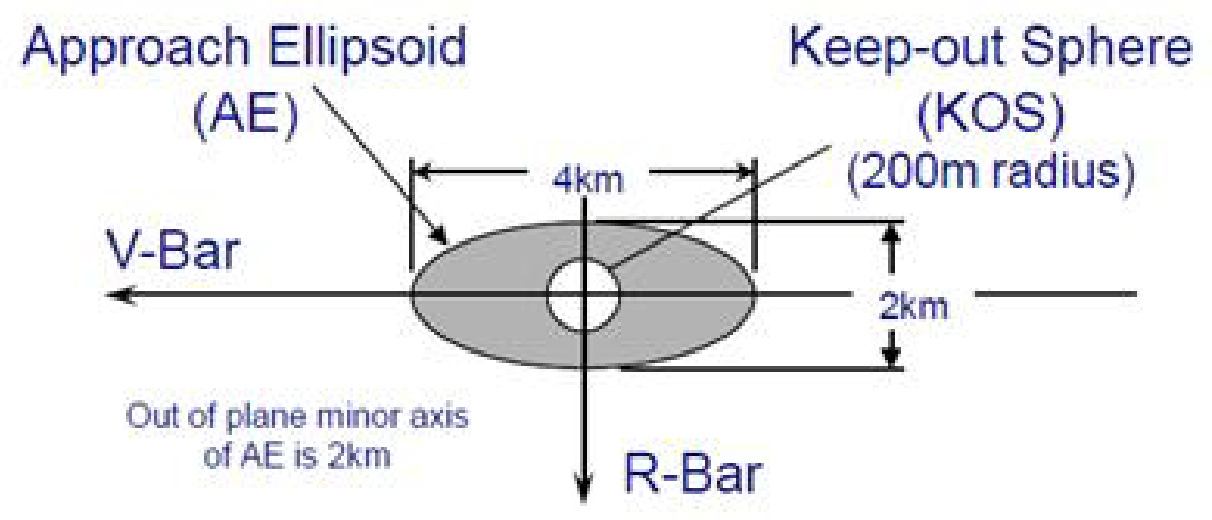


- Visiting Vehicles are necessary for continued operation of the ISS.

- Each Visiting Vehicle is able to meet all the ISS safety and mission requirements through their unique vehicle design.

- Sufficient margins are built into their design to account for worstcase on-orbit conditions.

- VVs have provided the bulk of the total ISS propellant consumed since the FGB was launched in 1998 with a total of $\sim 70,000 \mathrm{~kg}$

- Using the requirements laid out in the SRD, IRD, and the flight rules, the ISS Program has successfully docked or berthed visiting vehicles over one hundred and twenty times throughout the fourteen years of its life.

- United effort on part of all international and commercial partners in design and operation of visiting vehicles is vital to the continued operation of the ISS. 
1. Beisner, M., Kamath, U.P., Swanson, R.A., "HTV Propulsion Systems Databook", The Boeing Company, Publication No. D684-13625-01 Rev A, Houston, TX, Mar. 2011. Cincinnati, OH, July 2007.

2. Cross, A., Duffin, S., and Greenberg, Z. "Transient Surge Pressure Characterization of a Spacecraft Propulsion Subsystem due to Propellant Priming and Thruster Valve Cycling", JANNAF, JANNAF 2012-0001I, San Antonio, TX, May 2012.

3. "Interface Definition Document (IDD) for International Space Station (ISS) Visiting Vehicles (VVs)", NASA, SSP 50235, Houston, TX, Feb. 2000.

4. "International Space Station (ISS) to Commercial Orbital Transportation Services (COTS) Interface Requirements Document (IRD)", NASA, SSP 50808, Houston, TX, July 2007.

5. Karakulko, W., Russell, S., Sanders, G.B., Spencer, V., "Russian Propulsion and Propellant Resupply Systems for the ISS", NASA, JSC-27979 Rev. F, Houston, TX, Mar. 2010.

6. Kamath, U., Metrocavage, K., Russell, S., Spencer, V., Swanson, R.A., "On-Orbit Propulsion and Methods of Momentum Management for the International Space Station", AIAA, AIAA 2009-4899, Denver, CO, Aug. 2009.

7. Kamath, U.P., Krajchovich, M.C., Swanson, R.A., "ATV Propulsion and Propellant Resupply Systems Databook", The Boeing Company, Publication No. D684-13250-01, Houston, TX, Jan. 2009.

8. Keyser, L., "Apollo Experience Report - the Role of Flight Mission Rules in Mission Preparation and Conduct", NASA TN D-7822, Houston, TX, Nov. 1974.

9. Pedley, M.D., Internal Note to NASA EVA Project Office, "Propellant Contamination Issues - Potential Hazards to Crew", NASA, Houston, TX, Feb. 2001.

10. "Safety Requirements Document", NASA, SSP 50021 DCN 004, Houston, TX, July 2009.

11. "Space Systems - Composite Overwrapped Pressure Vessels (COPVs)", ANSI/AIAA, S-081A-2006, Reston, VA, July 2006.

12. Yamamoto, M., Nakai, S., Ishizaki, S., Matsuo, S., Imada, T., Russell, S., and Kamath, U.,"Surge Pressure Management in HTV Propulsion System," 43rd AIAA/ASME/SAE/ASEE Joint Propulsion Conference \& Exhibit, "Structural Design and Verification Requirements", NASA, SSP 30559 Rev D, Houston, TX, July 2007. 